\title{
Mycobacterium tuberculosis Shikimate Pathway Enzymes as Targets for the Rational Design of Anti-Tuberculosis Drugs
}

\author{
José E. S. Nunes ${ }^{1,2,+}$, Mario A. Duque ${ }^{1,3,+}$, Talita F. de Freitas ${ }^{1,2} \mathbb{D}$, Luiza Galina ${ }^{1,2} \mathbb{D}$, \\ Luis F. S. M. Timmers ${ }^{4}$, Cristiano V. Bizarro ${ }^{1,3} \mathbb{D}^{\mathrm{D}}$, Pablo Machado ${ }^{1,3}$, Luiz A. Basso ${ }^{1,2,3, *}$ \\ and Rodrigo G. Ducati $1,4,5, * \mathbb{D}$ \\ 1 Centro de Pesquisas em Biologia Molecular e Funcional (CPBMF) and Instituto Nacional de Ciência e \\ Tecnologia em Tuberculose (INCT-TB), Pontifícia Universidade Católica do Rio Grande do Sul (PUCRS), \\ Porto Alegre, RS 90619-900, Brazil; jeduardo.sacconi@gmail.com (J.E.S.N.); \\ alejandro.duquevillegas@gmail.com (M.A.D.); talita.freitas@acad.pucrs.br (T.F.d.F.); \\ luizagalina89@gmail.com (L.G.); cristiano.bizarro@pucrs.br (C.V.B.); pablo.machado@pucrs.br (P.M.) \\ 2 Programa de Pós-Graduação em Medicina e Ciências da Saúde, PUCRS, Porto Alegre, RS 90619-900, Brazil \\ 3 Programa de Pós-Graduação em Biologia Celular e Molecular, PUCRS, Porto Alegre, RS 90619-900, Brazil \\ 4 Programa de Pós-Graduação em Biotecnologia (PPGBiotec), Universidade do Vale do Taquari (Univates), \\ Lajeado, RS 95914-014, Brazil; luis.timmers@univates.br \\ 5 Centro de Ciências Médicas (CCM), Univates, Lajeado, RS 95914-014, Brazil \\ * Correspondence: luiz.basso@pucrs.br (L.A.B.); rodrigo.ducati@univates.br (R.G.D.); \\ Tel.: +(55)(51)33203629 (L.A.B.); +(55)(51)997609299 (R.G.D.) \\ + They are equal-contributing first authors.
}

Academic Editor: Laurent Chiarelli

Received: 27 December 2019; Accepted: 10 February 2020; Published: 11 March 2020

\begin{abstract}
Roughly a third of the world's population is estimated to have latent Mycobacterium tuberculosis infection, being at risk of developing active tuberculosis (TB) during their lifetime. Given the inefficacy of prophylactic measures and the increase of drug-resistant M. tuberculosis strains, there is a clear and urgent need for the development of new and more efficient chemotherapeutic agents, with selective toxicity, to be implemented on patient treatment. The component enzymes of the shikimate pathway, which is essential in mycobacteria and absent in humans, stand as attractive and potential targets for the development of new drugs to treat TB. This review gives an update on published work on the enzymes of the shikimate pathway and some insight on what can be potentially explored towards selective drug development.
\end{abstract}

Keywords: Mycobacterium tuberculosis; human tuberculosis; shikimate pathway; enzyme drug target; enzyme inhibition; rational drug design

\section{Introduction}

\subsection{Tuberculosis}

Mycobacterium tuberculosis is the main causative agent of human tuberculosis (TB). In 2018, approximately 10 million people developed TB, which resulted in 1.3 million deaths in HIV-negative and 300,000 deaths in HIV-positive patients. This recent report from the World Health Organization (WHO) indicated that, worldwide, approximately 400,000 people developed multidrug-resistant TB (MDR-TB), where M. tuberculosis strains are resistant to isoniazid and rifampicin, two of the most effective TB first-line drugs [1]. Even more concerning was the fact that $8.5 \%$ of MDR-TB patients were infected with extensively drug-resistant strains of $M$. tuberculosis (XDR-TB), MDR-TB strains that are 
resistant to any of the fluoroquinolones and to at least one of the three injectable second-line drugs. Hence, TB drug resistance represents a public health crisis and health security threat. The current treatment recommended by the WHO for cases of drug-susceptible TB is a 6-month regimen of four first-line drugs (isoniazid, rifampicin, ethambutol and pyrazinamide), with treatment success rates of at least $85 \%$. MDR-TB requires a longer and more complex treatment regimen, with more expensive and toxic drugs, and has treatment success rates of $56 \%$ [1].

Worldwide, approximately 1.7 billion people are estimated to have latent TB infection (patient is infected with M. tuberculosis but has no symptoms), caused by the presence of "persisters", being thus at risk of developing active TB during their lifetime [1]. Persisters are defined by a quiescent (non-growing or slow-growing) subpopulation of organisms that survive exposure to a bactericidal antibiotic, are genetically indistinct from drug-susceptible bacteria and can revive under antibiotic-free conditions [2]. They are associated with reduced metabolic rate, activated stress response and altered cell-wall permeability when compared to drug-susceptible bacilli, and are primarily established in macrophages or granulomatous lesions inside the human host. Besides being associated with latent infection, persisters are thought to contribute to the requirement for lengthy anti-TB treatment and to play a significant role in relapse [2]. Patients having latent TB represent a considerable reservoir of the bacilli.

The two main interventions employed to prevent new M. tuberculosis infections and their progression to active TB are the treatment of latent TB infection and the vaccination of children with the bacille Calmette-Guérin (BCG) vaccine $[1,3]$. Unfortunately, vaccination against sensitive and resistant strains of $M$. tuberculosis is not effective in preventing pulmonary TB in adults. Furthermore, the efficacy of $B C G$ vaccination against pediatric pulmonary $\mathrm{TB}$ ranges from no protection to very high protection $(0-80 \%)$ [4]. New strategies are thus needed to combat TB worldwide.

\subsection{Drug Screening}

The publication of the complete $M$. tuberculosis genome sequence [5] offered opportunities to implement screening campaigns focused on the identification of low molecular mass chemical compounds that inhibited the activity of target enzymes. These protein targets were selected based on gene essentiality and were purified, crystallized and had their binding sites identified. Although target-based enzymatic assays, which evaluate in vitro inhibition of protein activity and small chemical compounds with lower inhibition dissociation constant values (larger affinity values), are selected based on the assumption that they will be translated into target specificity, these efforts have not yielded new anti-TB agents, as target-based in vitro screening of enzyme inhibitors neglect essential factors, including cell wall permeability, metabolic stability and target vulnerability [6]. With few exceptions that confirm the norm, current antibacterial drugs and compounds in clinical trials target well-established functions in macromolecular synthesis, namely, cell wall, protein and nucleic acids [7]. Indeed, all current TB drugs were discovered in whole-cell screens for inhibition of M. tuberculosis growth or growth of a surrogate of M. tuberculosis [6].

Accordingly, there has been a revival on the interest of phenotypic drug discovery approaches based on their potential to address the incompletely understood complexity of diseases, their promise of delivering first-in-class drugs and major advances in the tools for cell-based phenotypic screening [8]. Ideally, phenotypic drug discovery campaigns utilize physiologically relevant models that are linked to patient-derived biology, which in turn may self-select small molecule phenotypic hits affecting pathways and protein targets most relevant to the disease of interest [9]. Although phenotypic drug screening interrogates a larger molecular target space, primary hits are rarely target-specific $[8,10]$. It has been pointed out that the classification of drugs as "phenotypically discovered" is somewhat inconsistent and that the majority of successful drug discovery programs combine target knowledge and functional cellular assays to identify drug candidates with the most advantageous molecular mechanism of action [8]. A balanced approach thus appears to be more appropriate for chemotherapeutic development of anti-TB agents. Incidentally, a thorough review on target-based whole-cell phenotypic screening 
strategies for anti-TB drug discovery has been reported [6]. Target-based whole-cell screening is designed to identify compounds that can penetrate the cell envelope and inhibit the target protein within the cellular environment.

Advantages of the target-based approach to the development of new chemical entities (NCEs) to treat $\mathrm{TB}$ are as follows: 1) the ability of performing in vitro high-throughput screening campaigns, 2) the search and identification of lead compounds with defined molecular mechanisms against a defined target, 3) the analysis of compounds with a favorable cost/benefit ratio, 4) the development, even in the initial stages, of compounds with selective toxicity (e.g., enzymes of essential pathways that are absent from the human host), 5) structural data of the target, when available, help guide medicinal chemistry efforts to improve pharmacodynamics and pharmacokinetics, 6) the pre-clinical evaluation of lead compounds and 7) generation of patents if a new chemical scaffold is proposed. Moreover, phenotypic screening efforts may be followed by identification of target(s) and, if amenable, heterologous expression, purification, protein assay and structural determination to help guide medicinal chemistry efforts (closing full circle). In both cases, small molecule prioritization from target-based drug discovery and phenotypic drug discovery would benefit from a deeper appreciation of the mode of action and target engagement profile [9].

\subsection{Preferable Characteristics of Targets and Enzyme Inhibitors/Anti-TB Agents}

Amongst limitations of the target-based approach is that the target may not be relevant in the disease pathogenesis setting, thus placing a major emphasis on target validation. An ideal target for antibiotic development should be essential for in vivo growth of the pathogen, be drug vulnerable and be druggable. A typical first step to establish essentiality of a gene product is genome manipulation of bacilli (knockout experiments). Interestingly, mycobacterial CRISPR interference has recently been employed for the rapid validation of target essentiality and compound mode of action [11]. However, not all essential gene products are equally vulnerable to drug mode of action and the target must be accessible to chemical inhibition [6]. An essential gene product that requires drug binding to $100 \%$ of intracellular protein target sites is not vulnerable as the required high target engagement to effect a physiological change is unlikely to be achieved in the intracellular context. Therefore, a druggable target should be both essential and vulnerable.

A druggable target can be reached and influenced by a particular chemical compound and the characteristics of its cognate-compound binding sites are as follows-be of reasonable size, enclosure (not extensively exposed to solvent) and hydrophobic with unexceptional hydrophilicity (sites with increased polarity are less likely to be druggable). The target site size is an important indicator of druggability, as the larger the better for opportunities to make chemical modifications to optimize physicochemical properties (e.g., solubility) without affecting ligand binding affinity to protein target [12]. It is desirable that a three-dimensional structure of a protein target be available and, in the case of enzymes, that a direct and continuous method is feasible for in vitro biological activity determination (assayability) to enable high-throughput screening of chemical compounds [13]. If the target is an enzyme, it should bind the chemical compound with larger affinity than substrate(s), the chemical compound should inhibit enzyme activity at concentrations that are compatible with its physicochemical properties (e.g., solubility) and lead to cell dysfunction (e.g., attenuated growth or cellular killing).

Enzyme inhibitors and inactivators comprised roughly half of all marketed drugs [14]. A thorough understanding of the chemical and catalytic mechanisms of a protein target is pivotal to guide efforts of medicinal chemists to improve target affinity. Understanding the course of an enzyme-catalyzed chemical reaction can help conceptualize different types of inhibitors and inform the design of screens to identify desired mechanisms [15]. The determination of the type of inhibition of chemical candidates is needed as there are preferable modes of action of enzyme inhibitors for hits to move forward in optimization efforts. 
Ideally, new chemical agents to treat TB should [6,7]: 1) be effective against MDR- and XDR-TB (preferentially have a novel mechanism of action), 2) shorten treatment time (targeting nonreplicating bacilli and being effective in sterilizing the diverse subpopulations of $M$. tuberculosis in the human host), 3) be compatible with current antitubercular and HIV therapeutics (since TB/HIV co-infection is prevalent), 4) have favorable pharmacokinetic and pharmacodynamics profiles (manageable host metabolism profile and good oral bioavailability), 5) be chemically stable, 6) have appropriate physicochemical properties (e.g., aqueous solubility and absence of polymorphs), 7) have low cost of synthesis and as ultimate aspiration, 8) achieve a stable and relapse-free cure of TB. Interestingly, it has been proposed that targeting host lipid droplets in foamy macrophages may enhance efficacy of anti-TB agents. The lipophilic antibiotics stored in lipid droplets would be transferred to the intracellular pathogen as M. tuberculosis consumes host lipid droplets as a carbon source for growth [16].

The following section gives a description of the M. tuberculosis shikimate pathway enzymes as targets for the rational design of chemotherapeutic agents to treat TB. All the data was obtained from experimental results published in international journals, the great majority of which being indexed to PubMed. General keywords used for the searches were a combination of "enzyme name"/shikimate pathway, Mycobacterium tuberculosis, enzyme inhibition, (enzyme) drug target, etc. In this review, we have covered publications ranging from 1954 to 2019.

\section{The Shikimate Pathway}

The biosynthesis of aromatic rings from carbohydrate precursors in microorganisms and plants involves a range of extraordinary chemical transformations that together constitute the shikimate pathway; through seven enzymatic steps (Figure 1), phosphoenolpyruvate (PEP) and D-erythrose 4-phosphate (E4P) are condensed to the branch point compound chorismate (end product), which leads to several additional terminal pathways [17]. 


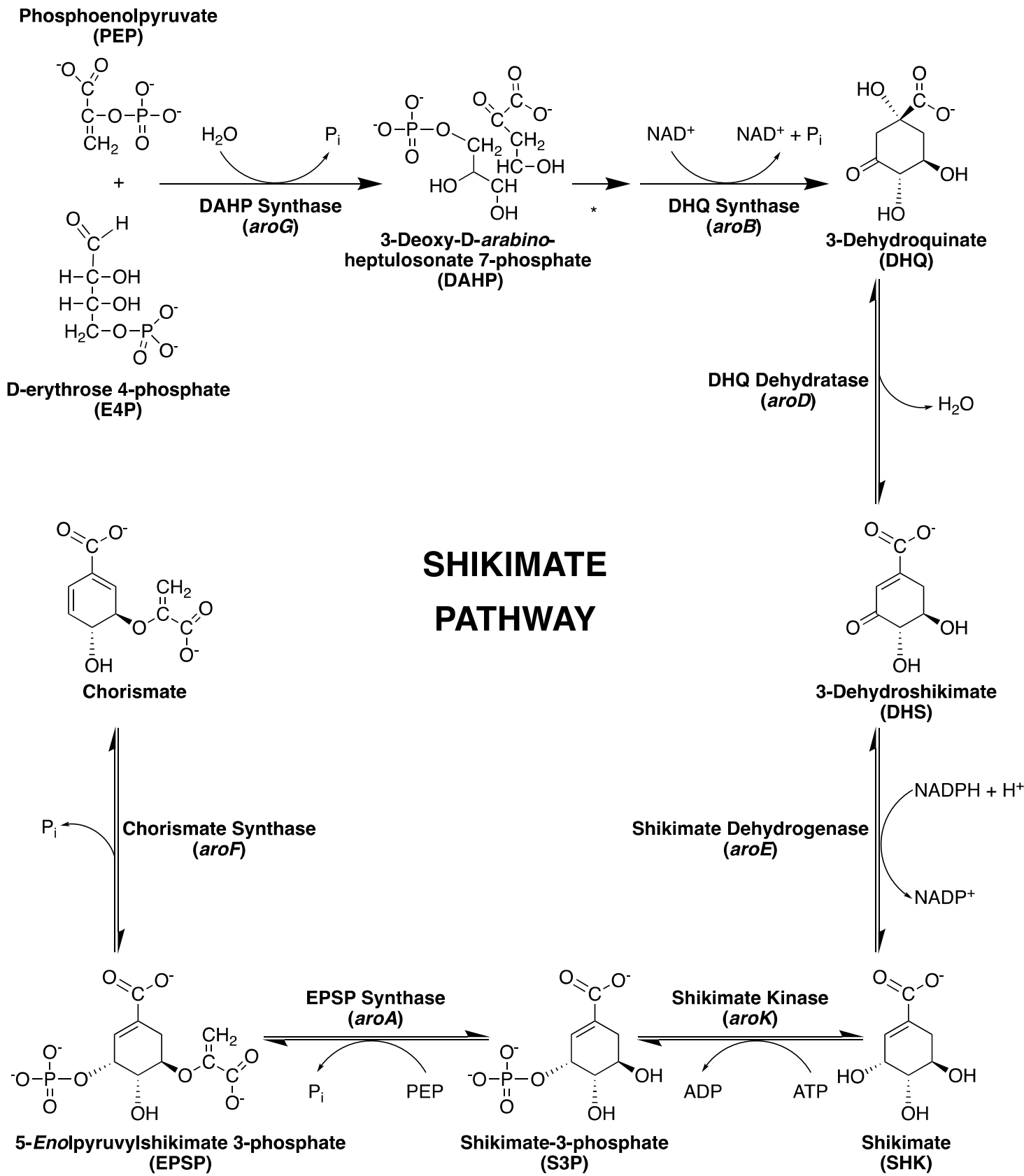

Figure 1. The shikimate pathway. The gene coding for each enzyme is in parenthesis. * Spontaneous cyclization of 3-deoxy-D-arabino-heptulosonate 7-phosphate (DAHP). $\mathrm{P}_{\mathrm{i}}=$ inorganic phosphate.

The shikimate pathway is an attractive target for the development of herbicides and antimicrobial agents because it is essential in algae, higher plants, fungi, bacteria and apicomplexan parasites but absent from mammals [18-22]. The mycobacterial shikimate pathway leads to the biosynthesis of chorismic acid, which is converted by distinct enzymes to prephenate (precursor of phenylalanine and tyrosine), anthranilate (precursor of tryptophan), aminodeoxychorismate (precursor of para-aminobenzoic acid-PABA—which, in turn, leads to tetrahydrofolate synthesis), para-hydroxybenzoic acid (precursor of ubiquinone or Coenzyme $Q$ ) and isochorismate (common precursor of naphthoquinones, menaquinones and mycobactins) (Figure 2). 


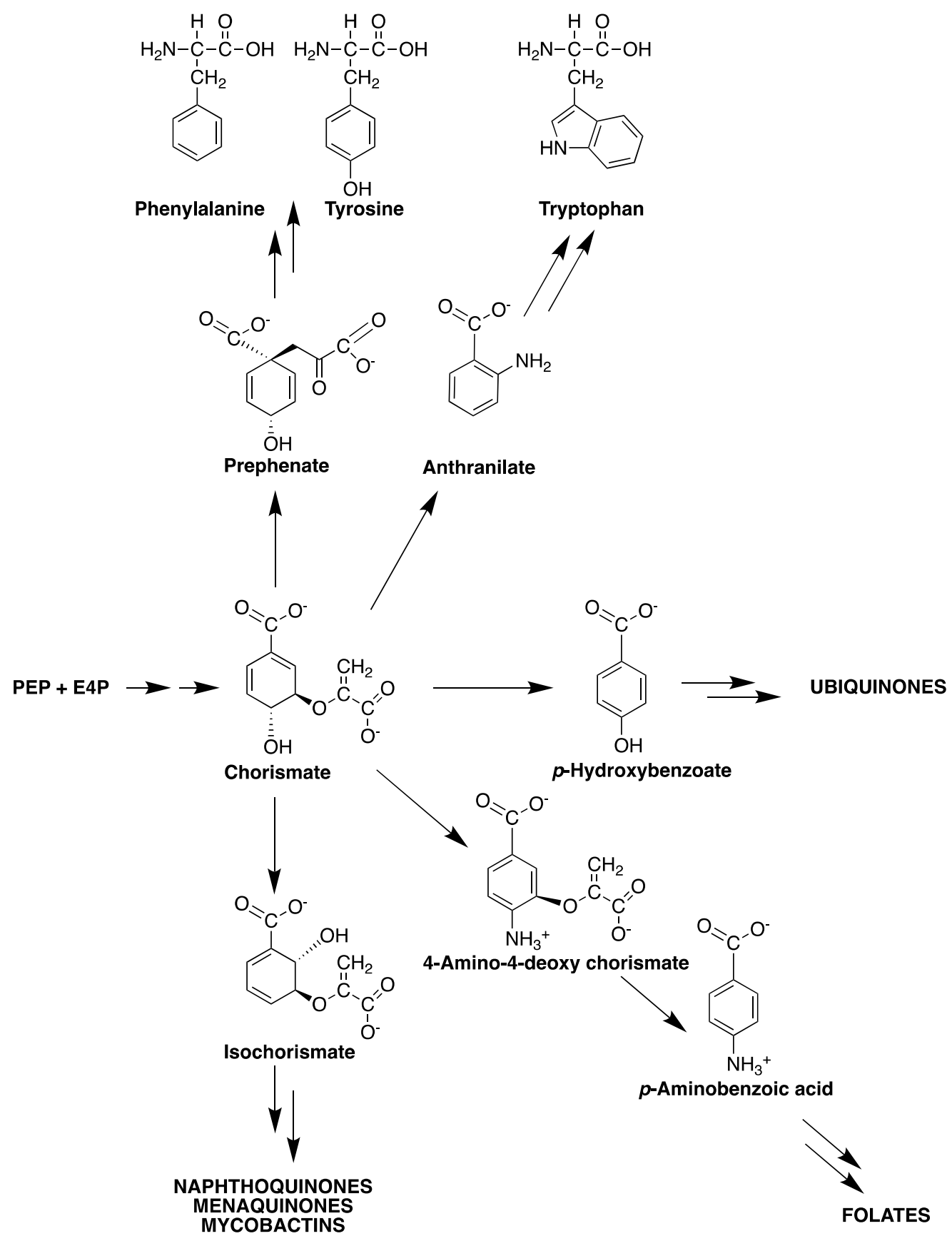

Figure 2. Chorismate: a metabolic node.

The mycobacterial genetic determinants (the "counteractome") allow these cells to overcome the host defense, which attempts to starve mycobacteria of tryptophan by a CD4 T cell-mediated killing mechanism. M. tuberculosis, however, can synthesize tryptophan (from chorismate precursor) under stress conditions and, thus, starvation fails [23]. Accordingly, inhibition of any enzyme of the mycobacterial shikimate pathway should preclude tryptophan biosynthesis and thereby increase the likelihood of starvation as an efficient mechanism of killing afforded by the human host.

\subsection{3-Deoxy-D-Arabino-Heptulosonate-7-Phosphate Synthase (aroG Coding Sequence; EC 2.5.1.54)}

The first component enzyme in the shikimate pathway (Figure 1), 3-deoxy-D-arabinoheptulosonate-7-phosphate synthase (DAHPS), catalyzes the first committed step in the biosynthesis of aromatic compounds in plants and microorganisms. This enzyme is responsible for an aldol 
condensation reaction between PEP and E4P to produce 3-deoxy-D-arabino-heptulosonate 7-phosphate (DAHP) and inorganic phosphate [24,25]. DAHPS enzymes are currently classified into two distinct families - type I and type II-based on their amino acid sequence and molecular mass. Type I enzymes have a molecular mass of approximately $40 \mathrm{kDa}$ and can be divided into two sequence subfamilies, I $\alpha$ and I $\beta$. Type II enzymes are larger, with molecular masses over $50 \mathrm{kDa}$. Although there is less than $10 \%$ sequence identity between types I and II, all DAHPS enzymes share a common $(\beta \alpha)$ TIM barrel catalytic domain, with extra-barrel elements related to allosteric function [26-28]. DAHPS activity is allosterically regulated by all three aromatic amino acids produced by the pathway-phenylalanine (Phe), tyrosine (Tyr) and tryptophan (Trp) - therefore being the major flow control point for the shikimate pathway $[17,26]$.

In Escherichia coli there are three structural genes—aroF, aro G and aroH-coding distinct type I $\alpha$ DAHPS enzymes, each has different extensions on $(\beta / \alpha)$ barrel domain and an $N$-terminal barrel extension, which provide a single allosteric binding site that is selective for either Phe, Tyr or $\operatorname{Trp}[17,29,30]$. Thermotoga maritima possesses a single DAHPS type I $\beta$, which contains an N-terminal domain associated with a single binding site for Tyr. In M. tuberculosis, sequence homology analysis revealed a single gene predicted as aroG (1389 bp), coding a type II DAHPS enzyme (MtDAHPS) [31]. Overall, the catalytic activity of DAHPS depends on the presence of a divalent metal ion in the active site. The activity of EDTA-treated apo MtDAHPS could be restored in assays containing $\mathrm{Co}^{2+}, \mathrm{Mn}^{2+}, \mathrm{Cd}^{2+}, \mathrm{Cu}^{2+}, \mathrm{Zn}^{2+}$ and $\mathrm{Ca}^{2+}$, with $\mathrm{Co}^{2+}$ and $\mathrm{Mn}^{2+}$ yielding the best results for restoring activity [28]. Furdui and coworkers [32] conducted experiments demonstrating that, in the case of $E$. coli DAHPS, the metal ion in the active site of the enzyme seems to play a structural role, orchestrating the arrangement of the active site residues in a position favorable for water activation. In this view, the geometry coordination of different metal ions may be a valuable factor for rational inhibitor design.

Previous studies have shown that the MtDAHPS reaction follows an ordered sequential mechanism, similar to those described for P. aeruginosa, Helicobacter pylori and Xanthomonas campestris type II DAHPS enzymes characterized to date $[28,33,34]$. The chemical mechanism described begins with a nucleophilic attack of PEP at the E4P aldehyde moiety, resulting in the formation of an oxocarbenium species $\mathbf{A}$ (Figure 3), which can be attacked by an active site water to form a phosphohemiketal intermediate B. This water molecule can potentially attack from either face of the oxocarbenium ion $\mathbf{A}$, giving rise to two possible diastereoisomers of the tetrahedral intermediate phosphohemiketal $\mathbf{B}$, differing in their absolute configuration at C2. Although this stereogenic center is transient and the stereochemical formation is lost by the elimination of phosphate in the final step to generate the product DAHP $\mathrm{C}$, the geometry of the enzyme's active site is likely to favor stereoselective attack of water to form one diastereoisomer tetrahedral intermediate phosphohemiketal A, preferentially. Thereby, DAHP is formed in its acyclic form and cyclizes into its cyclic pyranose form following release from the enzyme's active site [35].
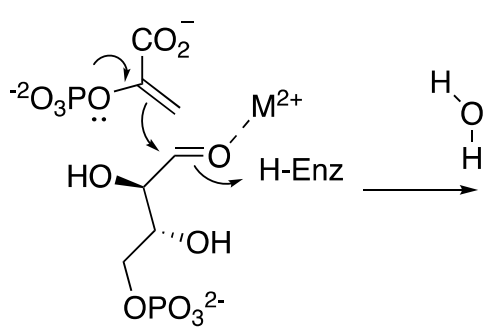

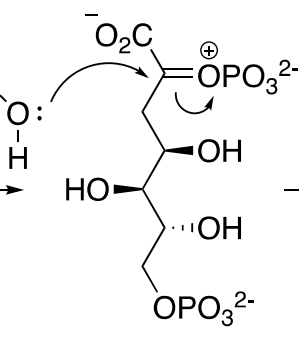

A

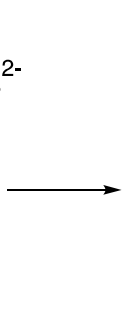

(1)

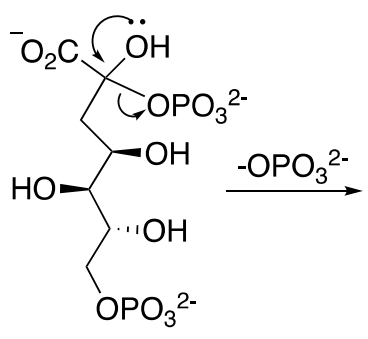

B

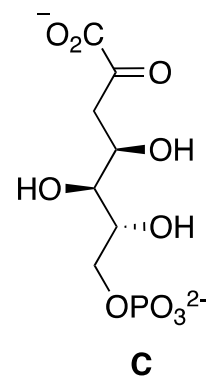

C

Figure 3. Overall proposed chemical mechanism of condensation of PEP with E4P. H-enz = H-enzyme.

The crystallographic structure of MtDAHPS (PDB 2B7O) revealed a homotetrameric quaternary structure whose dimeric and tetrameric interfaces are formed by accessory interactions between $(\beta / \alpha)$ 8 TIM barrel subunits (Figure 4a) [28]. The structure also enabled the identification of possible catalytic 
(and essential) amino acid residues at the active site revealing a network of hydrogen bonds between phosphate and carboxylate groups from the protein and PEP, which defines the binding site for the substrate (PEP). The analysis of the structure showed that the PEP phosphate group makes hydrogen bonds with the $\mathrm{NH}_{2}$ group of Lys306, the $\delta$-guanido groups of Arg284 and Arg337, the amide nitrogen of Glu283 and with two water molecules (Figure $4 b$ ). The PEP carboxylate group forms a double hydrogen bond with the $\delta$-guanido group of Arg126 and one additional hydrogen bond with the $\varepsilon$-amino group of Lys306 and one water molecule. Thus, each carboxylate oxygen atom receives two hydrogen bonds with favorable geometry for the molecular recognition of substrates at the enzyme's active site (Figure $4 \mathrm{~b})$. Furthermore, a sulfate ion $\left(\mathrm{SO}_{4}{ }^{2-}\right)$ is bound in the active site region near its opening and approximately $10 \AA$ away from PEP. This ion marks the likely position of the phosphate group from E4P and makes hydrogen bonds with amino acid residues Arg135, Arg284 and Ser136. Arg284 provides a bridge between PEP and sulfate, where there is one hydrogen bond between the residue and the PEP phosphate group and another hydrogen bond between the residue and the sulfate ion. The metal binding site is formed by four ligands-the $S \gamma$ of Cys87 (from the $\beta 1-\alpha 1$ loop), N 22 of His369 (from the $\beta 7-\alpha 7$ loop), O 22 of Glu411 (from the end of strand $\beta 8$ ) and O 82 of Asp441 (from the $\beta 8-\alpha 8$ loop). Cys87 and His369 are the axial ligands, with Glu411 and Asp441 in the equatorial trigonal plane, leaving one equatorial site available for the binding of E4P or water. An interesting feature of the metal site is the presence of Cys440 close to the metal ligand Cys87. A simple rotation at Cys440 C $\alpha-C \beta$ to another rotamer would allow formation of a disulfide bond with Cys87 precluding metal binding (Figure $4 \mathrm{~b}$ ). This explains the need for a reducing agent to maintain full activity of the enzyme [28]. However, the importance of the amino acid residues mentioned above for the catalytic mechanism of $M t D A H P S$ has not been experimentally demonstrated and the knowledge of their identity can be important not only for understanding enzyme function but also for potential use in drug design. 
(a)

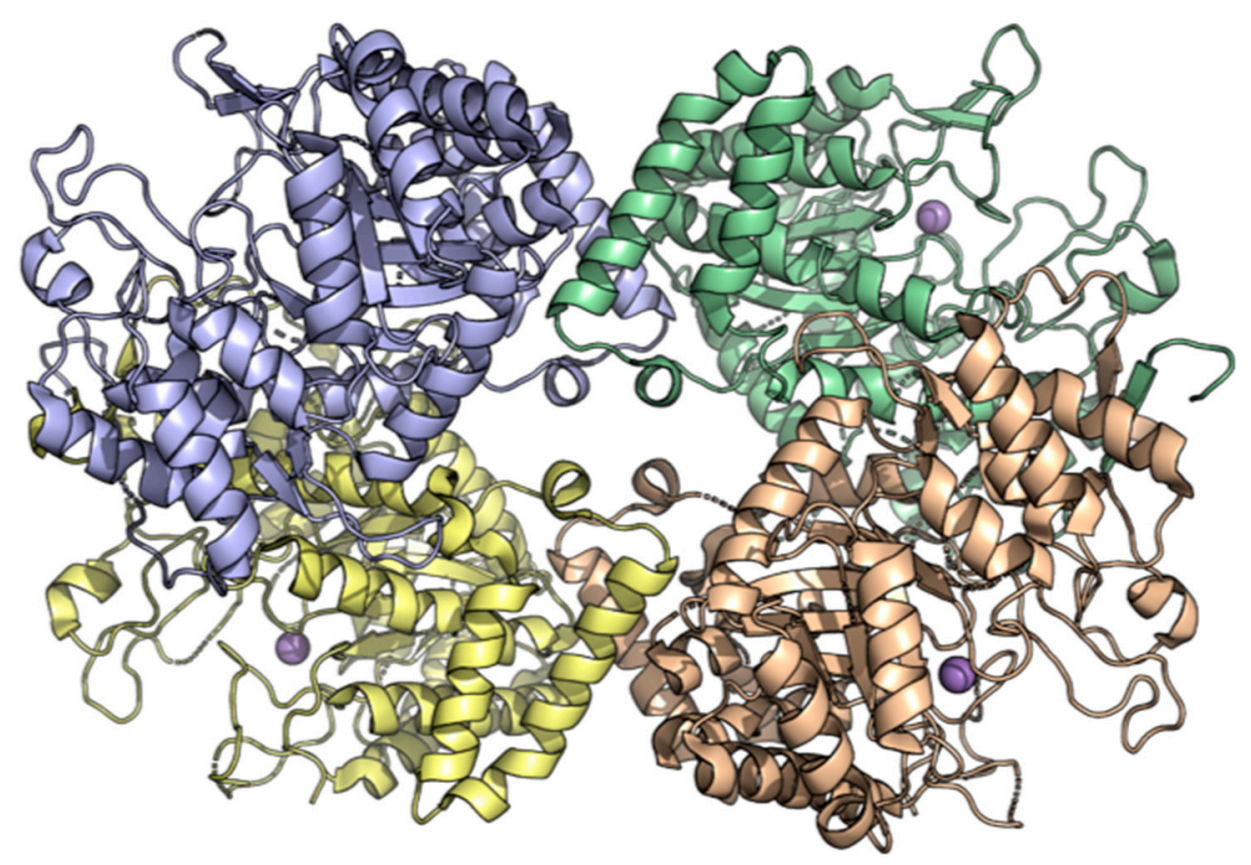

(b)

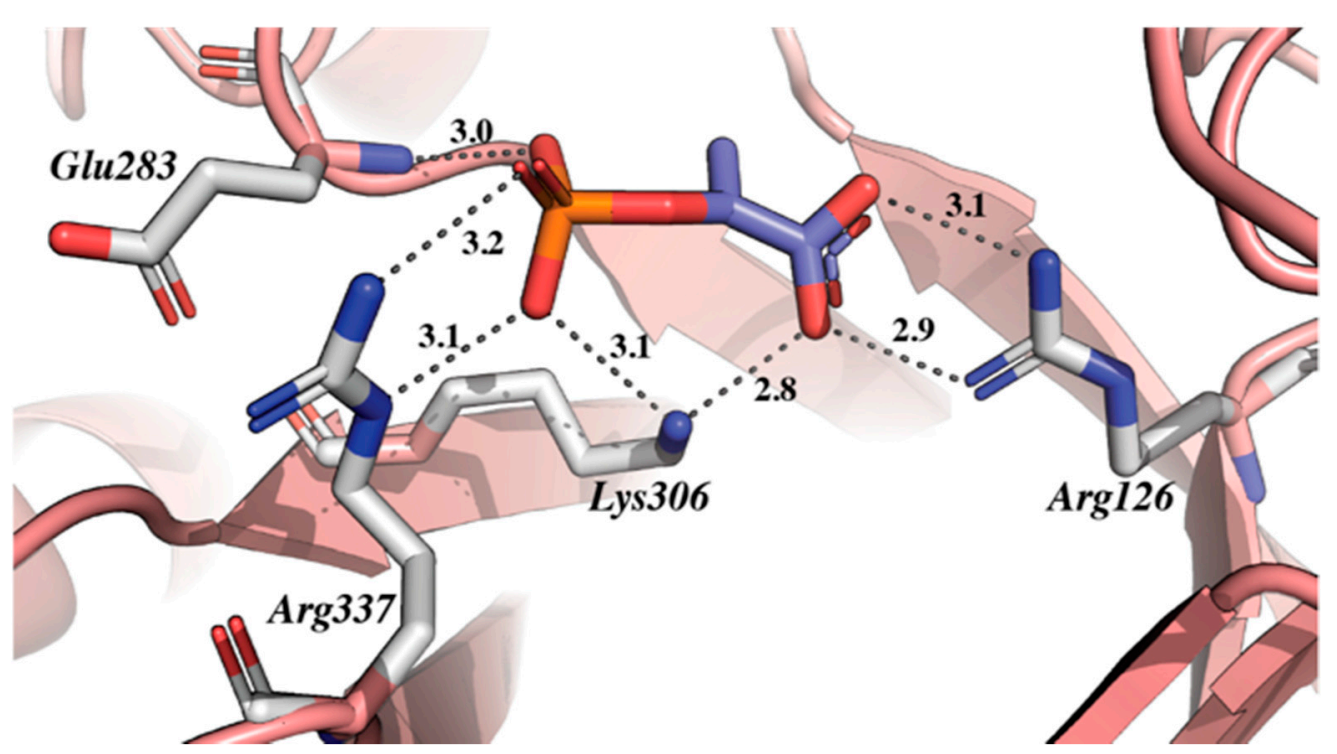

Figure 4. The structure of MtDAHPS. (a) Structure of the MtDAPHS tetramer showing monomeric units. $\mathrm{Mn}^{2+}$ ions at the MtDAHPS active site are shown as purple spheres. (b) Active site of MtDAHPS showing the interactions with the PEP substrate (orange and purple stick model). The images were generated on PyMOL.

Previous studies have shown that MtDAHPS possesses a highly sophisticated mechanism of allosteric control due to an N-terminal extension and a loop extension. These extra-barrel elements provide three distinct binding sites that are selective for either Phe, Tyr or Trp. Site 1, occupied by Trp, is located on the tetrameric interface and consists mainly of the amino acid residues of the $\alpha 2 \beta 3$ loop extension and the helix $\alpha 1$. Site 2 is occupied by Phe and/or Tyr and is on the dimeric interface, covered by sheet $\beta 0$ of the TIM barrel N-terminal extension. Site 3 is located between the N-terminal extra-barrel portion ( $\alpha 0 \mathrm{a}$ and $\alpha 0 \mathrm{~b}$ helices) and the $\alpha 3$ helix of the main barrel; Phe and/or Tyr occupy this site at high concentrations $(2 \mathrm{mM})$. Even though not inhibited by individual aromatic amino acids, binary combinations with Trp and either Phe or Tyr result in significant loss of MtDAHPS activity and the ternary combination of all three aromatic amino acids completely abolishes the 
enzyme-catalyzed chemical reaction, suggesting synergy in response to these allosteric effectors [36,37]. Furthermore, MtDAHPS also forms a non-covalent hetero-octameric complex with $M$. tuberculosis chorismate mutase $(M t C M)$, which acts at the branch point that connects the shikimate pathway to Phe and Tyr production $[26,37,38]$. This complex formation not only activates $M t C M$ activity by more than two orders of magnitude but also allows $M t C M$ to share the allosteric machinery located on $M t$ DAHPS to direct the shikimate pathway end product-chorismate-towards either Trp or Phe and Tyr biosynthesis, based on metabolic requirements $[39,40]$. Interestingly, this remote control between DAHPS (the first enzyme of the shikimate pathway) and chorismate mutase represents a novel paradigm for regulation of this pathway [38].

Even though few inhibitor studies have been conducted targeting the mycobacterial enzyme, based on the crystal structure of MtDAHPS (PDB 2B7O), Reichau and coworkers [35] designed a bisphosphate molecule as a simplified analogue of the tetrahedral intermediate (Figure 5a) as a novel lead structure for inhibitors of MtDAHPS. This bisphosphate compound binds with its 2-phosphoryl and carboxylate moieties in the PEP binding site and in an extended conformation in the phosphate moiety on C7, located near the proposed E4P phosphate binding site. The bisphosphate forms salt bridges with Arg284, Arg337 and Lys306 and a hydrogen bond to the backbone N-H of Glu283. The carboxyl group forms salt bridges with Lys133 and Arg126 and coordinates to the manganese ion present in the active site. The 7-phosphate moiety extends into the tentative E4P phosphate binding site, forming salt bridges with Lys380 and Arg135 and hydrogen bonds with the Ser136 hydroxyl group and backbone N-H. Arg135 and Ser136 interact with the 7-phosphate moiety of the inhibitor, moving closer into the active site pocket. The side chain of Lys133 and the likely electrostatic repulsion with the guanidinium group of Arg135 shows the biggest conformational change of all active site residues, establishing a salt bridge to the carboxylate group of the bisphosphate. Synthesized enantiomer compounds (R)-bisphosphate and (S)-bisphosphate were used on inhibition assays, where inhibitory constants of $360 \pm 50 \mathrm{nM}$ and $620 \pm 110 \mathrm{nM}$, respectively, were determined. These results provide valuable insight to a lead structure for novel potent antimycobacterial drugs targeting $M t D A H P S$ [35].

(a)<smiles>O=CC(CCCCCO[S+](=O)[O-])(OP)C(=O)O</smiles>

(b)<smiles>O=Cc1cccnc1</smiles>

(c)<smiles>Cc1c(C)c2c(c(C)c1O)CC[C@](C)(CCC[C@H](C)CCC[C@H](C)CCCC(C)C)O2</smiles>

(d)<smiles>CC1O[C@H](OC[C@H]2O[C@H](Oc3c(-c4ccc(O)c(O)c4)oc4cc(O)cc(O)c4c3=O)[C@@H](O)[C@H](O)[C@H]2O)[C@H](O)[C@H](O)[C@H]1O</smiles>

Figure 5. Linear chemical structures of MtDAHPS inhibitors. (a) simplified bisphosphate, (b) 3-pyridine carboxyaldehyde, (c) $\alpha$-tocopherol, (d) rutin.

Furthermore, structure-based approach and E-pharmacophore based virtual screening identified 3-pyridine carboxyaldehyde, $\alpha$-tocopherol and rutin as lead compounds to inhibit MtDAHPS (Figure 5). Enzyme inhibition assays against MtDAHPS confirmed their inhibitory potential, suggesting that their structure could be exploited for future drug development [41]. Desmond stimulation interaction diagram for $\alpha$-tocopherol showed its interaction with Ser136, Asp138 and Gln37. 
For 3-pyridine carboxyaldehyde, there was a stable interaction with Arg399 and Lys 306. Rutin showed constant H-bond interaction with Arg284 andArg337. The percentage of enzyme inhibition for the lead compounds, $\alpha$-tocopherol, 3-pyridine carboxyaldehyde and rutin, were $21 \%, 17 \%$ and $16 \%$, respectively [41]. However, further efforts are needed to show whether these chemical compounds reach and inhibit MtDAHPS in the intracellular context and target engagement results in arrested growth of bacilli.

\subsection{3-Dehydroquinate Synthase (aroB Coding Sequence; EC 4.2.3.4)}

The second enzyme in the shikimate pathway (Figure 1), 3-dehydroquinate synthase (DHQS), is responsible for the generation of the first carbocyclic compound of the pathway, converting DAHP into 3-dehydroquinate (DHQ) [21,42,43]. In M. tuberculosis, DHQS is encoded by the aroB gene, differing from microbial eukaryotes where this homologue is part of a multifunctional enzyme complex (encoded by the AROM gene) capable of conducting the five central steps of the pathway [44-46]. The mycobacterial enzyme has the extraordinary ability to conduct six chemical reactions (Figure 6) in a single active site, which was considered by some a marvel feat, attracting interest on the enzyme's structure and chemical mechanism [46-48].

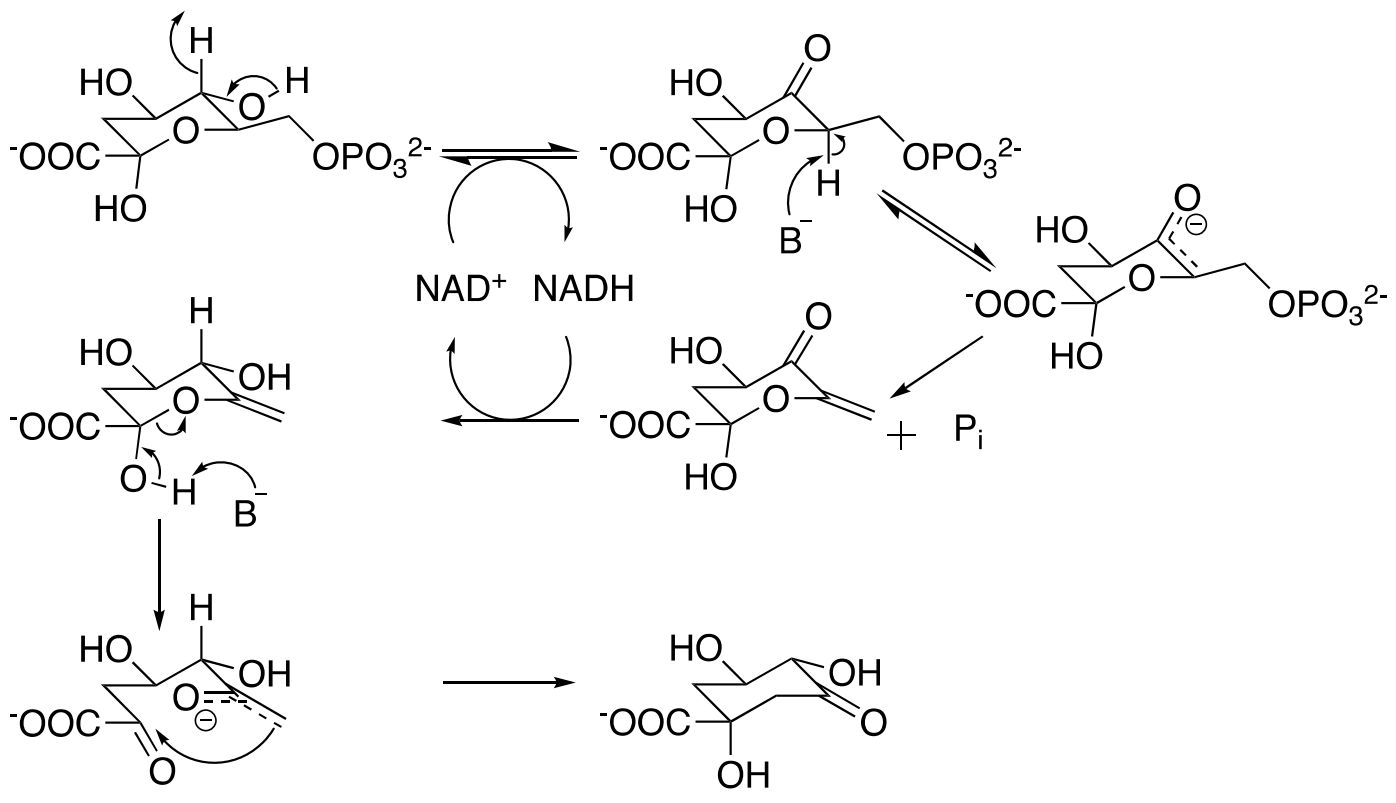

Figure 6. Multi-step reaction catalyzed by MtDHQS.

The cloning and functional demonstration of MtDHQS activity was first reported by Mendonça and coworkers [49] and studies on its kinetic mechanism were subsequently performed [50]. Initial velocity measurements and fluorescence binding studies point to a rapid equilibrium ordered mechanism, with $K_{\mathrm{M}}$ values of $6.3 \mu \mathrm{M}$ for DAHP and $70 \mu \mathrm{M}$ for NAD ${ }^{+}$. DHQS is a metalloenzyme, requiring a divalent cation for its activity. Incubation with EDTA abolishes enzyme activity, which can be restored by addition of $\mathrm{Co}^{2+}$ into the reaction mixture and by $\mathrm{Zn}^{2+}, \mathrm{Ca}^{2+}, \mathrm{Cd}^{2+}, \mathrm{Mg}^{2+}, \mathrm{Mn}^{2+}, \mathrm{Ni}^{2+}$ and $\mathrm{Ba}^{2+}$ to a smaller extent [50]. Although Cobalt seems to be more catalytically relevant, inductively plasma atomic absorption analysis of recombinant MtDHQS revealed the presence of Zinc in the enzyme preparation, probably due to the greater bioavailability of Zinc and in agreement with reports related to the DHQS domain of AROM from Aspergillus nidulans [51,52]. The kinetic constants for the cyclic reduction and oxidation of $\mathrm{NAD}^{+}$and $\mathrm{NADH}$, respectively, during the MtDHQS catalyzed reaction, were determined using a stopped-flow instrument, under single-turnover experimental conditions. The pre-steady-state kinetic data demonstrated that there is a transient increase in absorbance associated with NADH formation followed by its oxidation back to NAD ${ }^{+}$that occurs only in the presence of 
$M t$ DAHP-catalyzed conversion of DAHP to DHQ. In addition, the rates of $\mathrm{NAD}^{+} \rightarrow \mathrm{NADH} \rightarrow \mathrm{NAD}^{+}$ conversion are not rate limiting, since they are larger than the $0.63 \mathrm{~s}^{-1} k_{\text {cat }}$ value [50].

The chemical mechanism of E. coli DHQS was thoroughly investigated, dissecting each of the steps using substrate analogues to examine the early and late steps of the reaction, which are-binding to the enzyme, $\mathrm{C} 5$ oxidation by enzyme-bound $\mathrm{NAD}^{+}, \mathrm{C} 6$ enolization, $\beta$-elimination of the phosphate group, reduction at $\mathrm{C} 5$ regenerating $\mathrm{NAD}^{+}$, pyranose ring opening, and, finally, an aldol intramolecular reaction $[47,48]$. A set of analogue compounds that were uncapable of undergoing $\beta$-elimination revealed that the enzyme binds with higher affinity to shortened side chains and carbocyclic analogues. For example, a single carbon reduction in the side chain rendered a three order of magnitude improvement on inhibition, which agrees with a previous report [53]. Carbocyclic compounds seem to have an increased affinity for the enzyme due to the favored oxidation at $\mathrm{C} 5$, as shown by the levels of $\mathrm{NADH}$ found in the enzyme-analogue complexes when in equilibrium. The $\mathrm{C} 6$ enolization is proposed to be carried out by the attack of one of the phosphate oxygens present in the substrate (DAHP), acting as a base and extracting a proton from $\mathrm{C} 6$, preparing the group for the subsequent elimination step and giving evidence for a stepwise reaction [47].

Another set of analogues, uncapable of interconverting between the hemiketal and acyclic ketal proposed intermediates, was used to demonstrate that the enzyme is able to use a 2-deoxy analogue of DAHP as substrate, which generates a product that does not go through the last two reactions (pyranose ring opening and aldol intramolecular reaction). Additionally, the enzyme does not seem to be able to bind to acyclic analogues of DAHP. This data implicates that the enzyme may not be actively involved in these last two steps and that, instead, they occur spontaneously (either in solution or in the active site) [48]. Altogether, these data suggest that the enzyme is probably specialized in the redox reaction at $\mathrm{C} 5$, which triggers a cascade of spontaneous events that generate $\mathrm{DHQ}$, opposing an alternative hypothesis that this enzyme would have evolved to gather six catalytic groups into a single active site to carry out all the steps of the reaction. In fact, the structure of the AROM DHQS domain from $A$. nidulans shows that the enzyme coordinates a proton shuffling from the $\mathrm{C} 5$ hydroxyl group to a water molecule and then to His 275 in a concerted manner while the hydride transfer to $\mathrm{NAD}^{+}$occurs. A phosphate binding pocket positions the phosphate group so that one of the phosphate oxygens from DAHP can extract the proton from C6, resulting in the elimination of phosphate. There is little evidence for enzyme participation in the last two steps, corroborating the data from the study with substrate analogues [46].

Most of the analogues synthesized in the aforementioned studies $[47,48]$ turned out to be competitive inhibitors of $M t D H Q S$, although there is no report on probing their potential as drugs to target bacteria. Nonetheless, a recent publication revealed that DHQS is the main target of IMB-T130 (Figure 7) [54]. This promising molecule exhibited an $\mathrm{IC}_{50}$ of $2.7 \mu \mathrm{M}$ and a MIC of $312 \mathrm{ng} / \mathrm{mL}$ against $M$. smegmatis, a $1.36 \log$ reduction in the growth of intracellular mycobacteria infecting mouse macrophages, with low toxicity towards human embryonic kidney 293 and HeLa cells [55], showing this enzymes' potential as a druggable candidate.

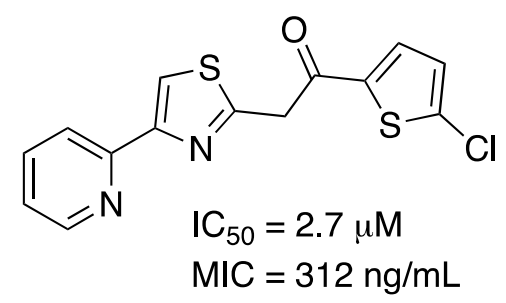

Figure 7. Structure of IMB-T130, a MtDHQS inhibitor.

\subsection{3-Dehydroquinate Dehydratase (aroD Coding Sequence; EC 4.2.1.10)}

Dehydroquinate dehydratase-also known as dehydroquinase (DHQase)—was originally identified in E. coli and is the third enzyme in the shikimate pathway (Figure 1), catalyzing the 
dehydration of DHQ into 3-dehydroshikimate (DHS) [56]. This enzyme possesses two distinct classes (types I and II) often correlated with the role in two different pathways-type I is present in the chorismate biosynthetic pathway from fungi, plants and some bacteria, while type II was considered part of the catabolic quinate pathway of fungi and in the shikimate pathway of most bacteria [57]. $M t D H Q a s e$ is one of the enzymes that indicated this classification could be misleading, as it is in fact a type II DHQase and part of the biosynthetic shikimate pathway [58]. Interestingly, types I and II DHQases seem to have evolved independently and are not related in sequence, structure or chemical mechanism [57-61].

Each type has its own stereospecificity $[59,60,62,63]$. Type I DHQases catalyze the dehydration with loss of the less acidic pro- $R$ hydrogen bound to $C 2$, with a covalently bound intermediate, a Schiff base formed between the $\mathrm{C} 3$ carbonyl group from the substrate and a conserved active site lysine followed by an enamine formation. A general base in the enzyme then extracts the proton from $\mathrm{C} 2$ and accepts the hydroxyl group in C1 leading to a syn-elimination $[60,64,65]$. In contrast, type II removes the more acidic pro-S hydrogen in accordance with the favored anti-elimination observed in acid or base catalyzed conversion of DHQ into DHS $[60,62,64]$. There is no covalent intermediate formed in this mechanism. A first proposition of an enolate intermediate was suggested by isotope effects studies [66] but new evidence of a structural water molecule would favor the formation of an enol intermediate before the exit of the $\mathrm{C} 1$ hydroxyl group [61].

Structurally, type I enzymes are homodimers in solution, with an eight stranded $\alpha / \beta$-barrel topology, a fold observed in other enzymes that form an imine intermediate $[57,65,67,68]$. $M t D H Q a s e$ displays a five-stranded parallel $\beta$-sheet core flanked by four $\alpha$-helices with a flavodoxin-like overall topology, being an homododecamer in solution (a tetramer of trimers) with 23 symmetry [57,69], in accordance with other type II DHQases from Streptomyces coelicolor, H. pylori, Acinetobacter baumannii and P. aeruginosa [61,70-72]. Tyr24 ( $M$. tuberculosis numbering) is conserved amongst type II enzymes and is proposed to be the base responsible for the extraction of the axial pro-S hydrogen [61,73]. Site-directed mutagenesis experiments showed that Arg23 (S. coelicolor numbering, equivalent to Arg19 in MtDHQase) is an essential amino acid for catalysis [74], although its role is not totally clear as it is present in a flexible loop composed by residues 19-24 (MtDHQase numbering) and it seems to approximate Tyr24 after substrate-binding, lowering its $\mathrm{pK}_{\mathrm{a}}$ and starting the reaction [75]. It is worth noting that MtDHQase classification as type II is based on structural and theoretical predictions. Enzyme kinetic studies (steady-state, pre-steady-state, $\mathrm{pH}$-rate profiles, isotope effects, surface plasmon resonance, spectrofluorimetry, microcalorimetry, mass spectrometry, borohydride trapping) on M. tuberculosis aroD-encoded (Rv2537c) DHQase should be pursued to offer a solid support for a chemical mechanism proposal and, consequently, for an adequate classification type to which this enzyme belongs.

An accurate distinction between types I and II is of critical importance in the design of inhibitors as the differences in active site and mechanism can be explored to develop highly specific inhibitors. Several reports on $M t D H Q a s e$ inhibition presented molecules displaying $K_{\mathrm{i}}$ vales in the nanomolar range [73,76-80], all of them being competitive analogues of DHQ substituted in either C2, C3 or both. The interactions of these compounds with the active site of $M t$ DHQase are driven mostly by two main features: (1) the presence of groups capable of forming $\pi$-staking interactions with Tyr24, like benzyl and benzothiophene groups attached to $\mathrm{C} 2$ or $\mathrm{C} 3$ and (2) groups that displace Arg19 outside the active site, blocking its interaction with Tyr24 $[75,80]$.

While the number of promising compounds with low $K_{\mathrm{i}}$ values is high and a solid support from structural data is available, the number of articles reporting effective inhibition on growth of $M$. tuberculosis is reduced. In a series of compounds generated by virtual screening with no resemblance to $\mathrm{DHQ}$, two lead molecules were identified with $\mathrm{IC}_{50}$ values of 17.1 and $31.5 \mu \mathrm{M}$ and MIC values against $M$. tuberculosis $\mathrm{H} 37 \mathrm{Rv}$ of 25.0 and $6.25 \mu \mathrm{g} / \mathrm{mL}$, respectively [69]. In another effort, a pharmacophore model was developed and screened against a library of natural compounds. Two molecules selected from the library that fulfilled all the characteristics of the model displayed 
some inhibition on M. tuberculosis growth with MIC values of $100 \mu \mathrm{g} / \mathrm{mL}$ [81]. Finally, another series of compounds based on DHQ monosubstituted on $\mathrm{C} 3$ or disubstituted on $\mathrm{C} 2$ and $\mathrm{C} 3$ generated nanomolar $K_{\mathrm{i}}$ values but had to be transformed into esters to display low $\mu \mathrm{g} / \mathrm{mL}$ MIC values [79]. The authors propose that increased hydrophobicity helps molecules cross the mycobacterial cell wall. Examples of these compounds are given in Figure 8.

(a)

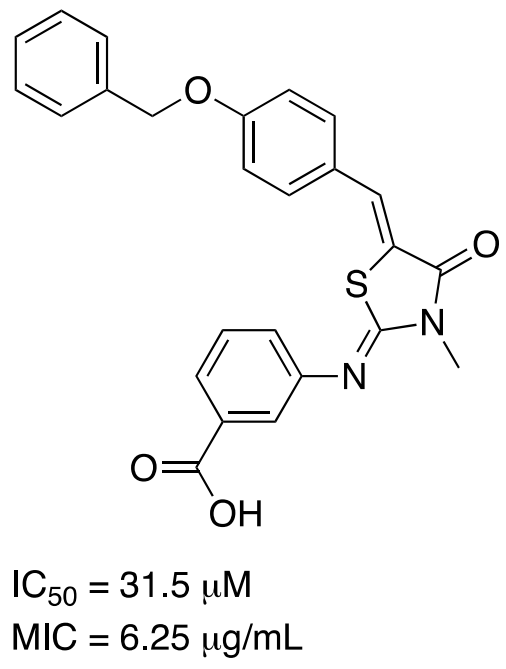

(b)<smiles>NC(=O)[C@H]1C[C@@](O)(C(N)=O)C[C@@H](O)[C@H]1O</smiles>

(c)<smiles>C=[14C][C@H](O)COC1OC(Oc2cc(O)c3c(c2)OC(c2ccc(O)cc2)CC3=O)C(OC2OC(C)C(O)C(O)C2O)C(O)C1O</smiles>

Figure 8. Structure of selected inhibitors of MtDHQase. (a) Molecule generated by virtual screening extracted from Petersen and coworkers [69]. (b) Example of nanomolar competitive inhibitor extracted from Tizón and coworkers [79]. *MIC obtained with the n-propil ester prodrug. (c) Natural occurring molecule (Narigin) found by virtual screening by Lone and coworkers [81].

\subsection{Shikimate 5-Dehydrogenase (aroE Coding Sequence; EC 1.1.1.25)}

The NADPH-dependent reduction of DHS is carried out by shikimate dehydrogenase (SD), the fourth enzyme in the shikimate pathway (Figure 1), generating the central metabolite shikimate (SHK). In some organisms, this point of the pathway intersects with the quinate catabolic pathway, where a second enzyme of the SD family is found, quinate dehydrogenase (QD), which catalyzes the reduction of both quinate and SHK, with first reports of the activity of the two enzymes from E. coli (SD) and Aerobacter aerogenes (QD) dating from about the same year (1955 and 1954, respectively) [56,82]. The presence of QD gives microorganisms the ability to use quinate as a carbon source, generating protocatechuate and proceeding to the $\beta$-ketoadipate pathway [83].

In most bacteria, SD is encoded by the aroE gene, like in E. coli, M. tuberculosis and Methanococus jannaschii [83-86], while QD is encoded by yidB in E. coli [83], qsuD in Corynebacterium glutamicum [87], QA-3 in Neurospora crassa [88] and qutB in A. nidulans [89]. In some fungi, such as A. nidulans, N. crassa and Saccharomyces cerevisiae and in the apicomplexan parasite Toxoplasma gondii, $\mathrm{SD}$ is part of the multifunctional AROM enzyme complex, while in some plants like Arabidopsis thaliana and Populus trichocarpa, the enzyme is found in a bifunctional enzyme complex, with the third step of the pathway DHQase [90]. Three other members of the SD family were identified as aminoshikimate dehydrogenase [91,92], SD-like enzymes [87,93] and AroE-like enzymes [94], though limited data is available on their mechanisms and substrate specificity. It is noteworthy that one pursuing the design of inhibitors for SD should be aware of the variety of members in this family and the possible mechanisms 
of resistance that may have already evolved in bacteria and plants as a result of either redundant activity or substrate preference, the latter of which cannot be translated into substrate specificity.

While sequence identity varies between family members, the structure is well conserved amongst them [90]. The structure of SD is comprised of two $\alpha / \beta$ architecture domains connected by a pair of $\alpha$-helices. The substrate biding site is located at the $\mathrm{N}$-terminus of the protein, shaped by a $\beta$-sheet (usually composed by six mainly parallel $\beta$-strands) surrounded by $\alpha$-helices. The dinucleotide biding site located at the C-terminus displays a classic Rossmann fold. A comparison between the aroE and $y d i B$ gene products from $E$. coli revealed small differences in the amino acid composition of the dinucleotide binding pocket that could explain variability of cofactor specificity found in the SD and QD enzymes and amongst other members of the family. NAD ${ }^{+}$binding in YdiB (PDB 1O9B) is favored by two amino acid substitutions compared to AroE (PDB 1NYT), which create in YdiB a more neutral environment compared to the basic binding pocket found in AroE [83]. In the MtSD models generated by our group, Arg149, Asn150 and Lys153 are present in equivalent positions to E. coli AroE Arg150, Thr151 and Arg154, which would explain the mycobacterial's enzyme preference for NADPH $[95,96]$. In Thermus thermophilus crystal structures, the DHS/SHK binding pocket (in the deep groove created between the two domains) reveals a set of polar amino acids capable of making hydrogen bonds with the hydroxyl groups of C3, C4 and C5 and, likewise, the carboxyl group at C1 [97]. The contacts with the $\mathrm{C} 1$ carboxyl and $\mathrm{C} 4$ hydroxyl groups are considered to be the most important for substrate recognition and catalysis, as mutations in the A. thaliana bifunctional enzyme DHQase-SD and S. epidermidis AroE enzymes showed a marked increase in $K_{\mathrm{M}}$ and decrease in $k_{\text {cat }}[98,99]$. These residues where found to be conserved in the MtSD structure model $[95,96]$.

A few reports on the kinetic mechanism of SD are available. Three independent studies revealed a consistent finding that SD enzymes follow a sequential bi-bi mechanism—ordered for Pisum sativum and M. tuberculosis $[95,100]$ and random for S. aureus [101]. However, kinetic data from the P. sativum enzyme suggests the binding of NADPH first, which is in contrast with the data from MtSD where DHS is proposed to bind first. The reported $K_{\mathrm{M}}$ values for SHK and cofactor are typically in the range of 50 and $200 \mu \mathrm{M}$ for bacterial SD enzymes (MtSD SHK $K_{\mathrm{M}}=50.2 \mu \mathrm{M}$ ) [85]. Turnover rates can vary greatly depending on the species, ranging from $361 \mathrm{~s}^{-1}$ in AroE from Archaeoglobus fulgidus to $1.5 \mathrm{~s}^{-1}$ in AROM from A. nidulans (MtSD $k_{\mathrm{cat}}=8.2 \mathrm{~s}^{-1}$ ) $[85,102,103]$. However, a better consensus is found considering the chemical mechanism. The hydride transfer from NADPH C4 to the DHS hydroxyl group on C3 is mostly conducted by two well conserved Lys and Asp residues, while a conserved Tyr seems to be important to position the cofactor in a catalytic competent manner $[90,95,96,98,104,105]$. Site-directed mutagenesis data suggest an important role in catalysis for both residues, as an impact on $k_{\text {cat }}$ was observed in A. thaliana [98] and on M. tuberculosis [105]. Data from pH-rate profiles and isotope effects on MtSD also indicates that the deprotonation of a residue with $\mathrm{pK}_{\mathrm{a}} \sim 8.9$ abolishes the activity of the enzyme [95]. Similar results were observed for Aquifex aeolicus [104]. Both research groups refer the conserved Lys or Asp as possible residues to explain the results. Solvent isotope effects also corroborate the transfer of a proton from solvent as being important for catalysis, indicating a probable acid-base catalysis mechanism, with a stereospecificity of the pro-S hydride from NAPDH C4 being transferred in a concerted manner [95], in contrast with SD partially purified from E. coli, which showed a preference for the pro- $R$ hydrogen [106]. Figure 9 presents the (a) kinetic and (b) chemical mechanisms of MtSD. 
(a)

$$
\mathrm{E}+\mathrm{DHS} \rightleftharpoons \mathrm{E}-\mathrm{DHS}+\mathrm{NADPH} \rightleftharpoons \mathrm{E}-\mathrm{DHS}-\mathrm{NADPH} \rightleftharpoons \mathrm{E}-\mathrm{SHK}-\mathrm{NADP}^{+} \rightleftharpoons \mathrm{E}-\mathrm{SHK} \rightleftharpoons \mathrm{E}
$$

(b)

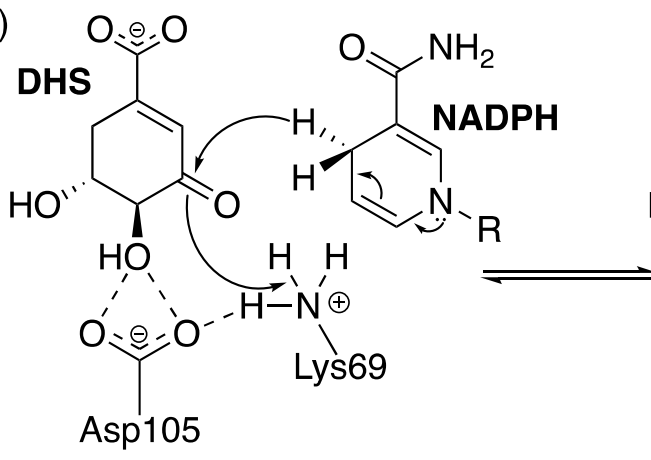

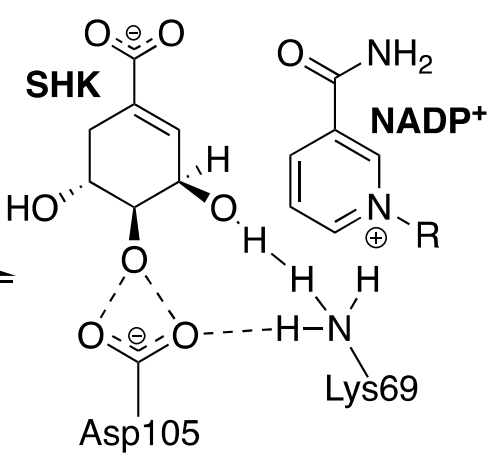

Figure 9. $M t S D(a)$ kinetic and (b) chemical mechanisms. R represents the ribose, adenosine diphosphate and $2^{\prime}$-phosphate moieties of NADPH.

Multiple SD inhibitors have been reported with $\mathrm{IC}_{50}$ values ranging from $\sim 3$ to $\sim 900 \mu \mathrm{M}$ [101,107-110], with only two reports showing MIC values of $\sim 500 \mu \mathrm{M}$ for a polyphenolic compound against P. putida [108] or shikimic acid derivatives against $E$. coli [109] and virtual screening derived compounds against $S$. aureus $\mathrm{SD}$ with $K_{\mathrm{i}}$ values ranging from $\sim 8$ to $\sim 100 \mu \mathrm{M}[101,110]$. There are three other reports on triazolothiadiazole inhibition of $M t S D$ presented $\mathrm{IC}_{50}$ values ranging from $\sim 7 \mu \mathrm{g} / \mathrm{mL}$ to $\sim 5 \mathrm{mg} / \mathrm{mL}$ and MIC values ranging from 0.25 to $8 \mu \mathrm{g} / \mathrm{mL}$ [111-113]. One of the drugs (named IMB-SD62) showed in vitro activity against MDR-TB and in vivo anti-TB activity with a $1.7 \mathrm{log}$ reduction in the CFUs in lungs and a preliminary pharmacokinetic study was performed demonstrating some potential for this class of molecules [113]. They display different inhibition mechanisms, which is valuable as they can turn into scaffolds for the design of several inhibition strategies against SD enzymes. A recent effort to identify potential molecules that bind to MtSD through virtual screening found three molecules (out of a library of 13,000 compounds) with favorable binding energies compared to SHK [114]. However, no experimental evidence of inhibition was presented to date. Examples of the different inhibitors are provided in Figure 10. 
(a)<smiles>COc1ccc(OCc2nn3c(-c4ccc(Br)cc4)nnc3s2)cc1</smiles>

(c)<smiles>[R3][R3]#[R]C(=O)C1CCC(c2ccc(C(=O)C3=NCCN3)cc2)S1</smiles>

(b)<smiles>Cc1c(O)ccc2c1OCC2=O</smiles>

(d)

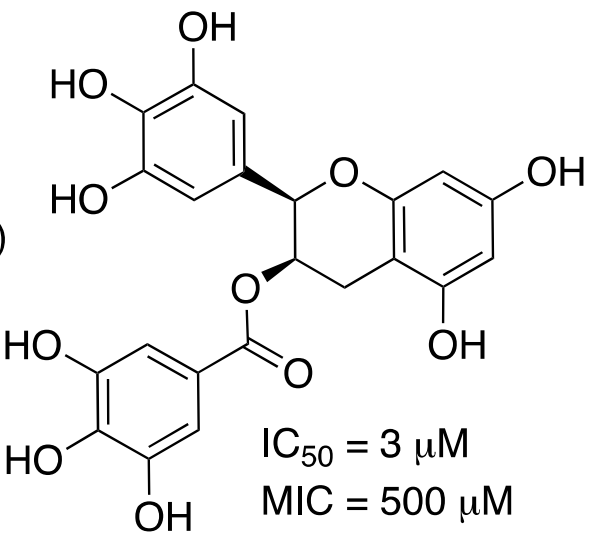

Figure 10. Examples of inhibitors of MtSD. (a) Triazolothiadiazole IMB-SD62, inhibitor of MtSD, extracted from Li and coworkers [111,113]. (b) and (c) S. aureus SD inhibitors extracted from Enríquez-Mendiola and coworkers [110]. (d) Polyphenolic, inhibitor of P. putida SD, extracted from Peek and coworkers [108].

\subsection{Shikimate Kinase (aroK Coding Sequence; EC 2.7.1.71)}

Shikimate kinase (SK), the fifth enzyme in the shikimate pathway (Figure 1), catalyzes the conversion of SHK into shikimate-3-phosphate (S3P) using adenosine $5^{\prime}$-triphosphate (ATP) as the co-substrate. The binding of ATP and SHK in the active site is guided by a conformational change of the flexible loop, promoting an open-to-closed conformation, followed by a rearrangement of domain movement for SK enzymes [115,116]. The release of S3P from the active site depends on the interaction with three conserved arginine residues-Arg117, Arg136 and Arg58. Arg117 triggers the process by forming a strong electrostatic interaction with the C3 phosphate group of S3P. The product undergoes a destabilization in the active center and a conformational change occurs, which in turn leads to a large opening of the extended SHK binding (ESB) and LID domains [117]. The catalytic turnover between SHK and ATP was studied in the crystalline environment. Based on a series of crystallographic studies with the enzyme in the apo form, binary and ternary complex, this study suggested that the random sequential binding of SHK and nucleotides is correlated with domain movements [115].

In E. coli, SK exhibits two isoforms that are encoded by different genes-aroK encodes for a shikimate kinase type I (SK I) and aroL encodes for a shikimate kinase type II (SK II). These enzymes have low sequence identity when compared to the mycobacterial enzyme, presenting $30 \%$ and $46 \%$ for SK I and II, respectively [118]. Other microbial genomes indicate a single SK coding sequence. In M. tuberculosis, SK is encoded by the aroK gene, producing an $18.6 \mathrm{kDa}$ protein with 176 amino acids. Two significant differences were observed by Gu and coworkers [119] in the substrate-binding (SB) domain between SK I and SK II. The first is the replacement of a phenylalanine residue (Phe49 in M. tuberculosis SK; MtSK) in SK I by a valine residue in SK II. The second difference is a shift of a glutamate residue (Glu54 in MtSK) in SK I by a tryptophan in SK II. It is important to observe that Glu54 (in MtSK) forms a hydrogen bond and a salt bridge with arginine (Arg58) and can help position the Arg58 guanidine group for SHK binding.

This enzyme belongs to the family of nucleoside monophosphate (NMP) kinases, a subfamily of the P-loop including the nucleoside triphosphate hydrolase superfamily [120,121]. This family undergoes 
large conformational changes during catalysis. A comparative study between Erwinia chrysanthemi SK (apo) and MtSK bound to ADP (binary complex) structures suggested that significant conformational changes occur upon nucleotide binding [119]. It was proposed by Dhaliwal and coworkers [122] that the binding of ADP induces a large hinged movement of the LID domain over the active site with Arg110 and Arg117, which is essential for the interaction with the nucleotide and repositioning of the SB domain observed.

$M t S K$ presents an $\alpha / \beta$ architecture, showing five central parallel $\beta$-strands flanked by $\alpha$-helices. The overall structure is divided into four domains [115]: (i) the ESB domain (residues 32-93), which enables rigid body movements, including the SHK binding (SB) subdomain (residues 32-61) that corresponds to the binding of NMP in NMP kinases, (ii) the nucleotide binding (NB) domain, responsible for the flexible regions constituting the nucleotide binding, formed by the phosphate binding P-loop (Walker-A motif; residues 9-17), adenine-binding (AB)-loop (residues 148-155) and the segment corresponding to residues 11-110, including $\alpha 6$ (residues 104-110), (iii) the LID domain (residues Gly112 to Asp124), responsible for opening and closing the catalytic site, allowing the interaction of the enzyme with substrates and products and (iv) the reduced core (RC) domain, covering NB domain and ESB segment (residues 62-93). Amongst all, the RC domain is the most rigid portion of the enzyme, whereas the LID and NB domains are the most flexible regions (Figure 11) [119,120,123].

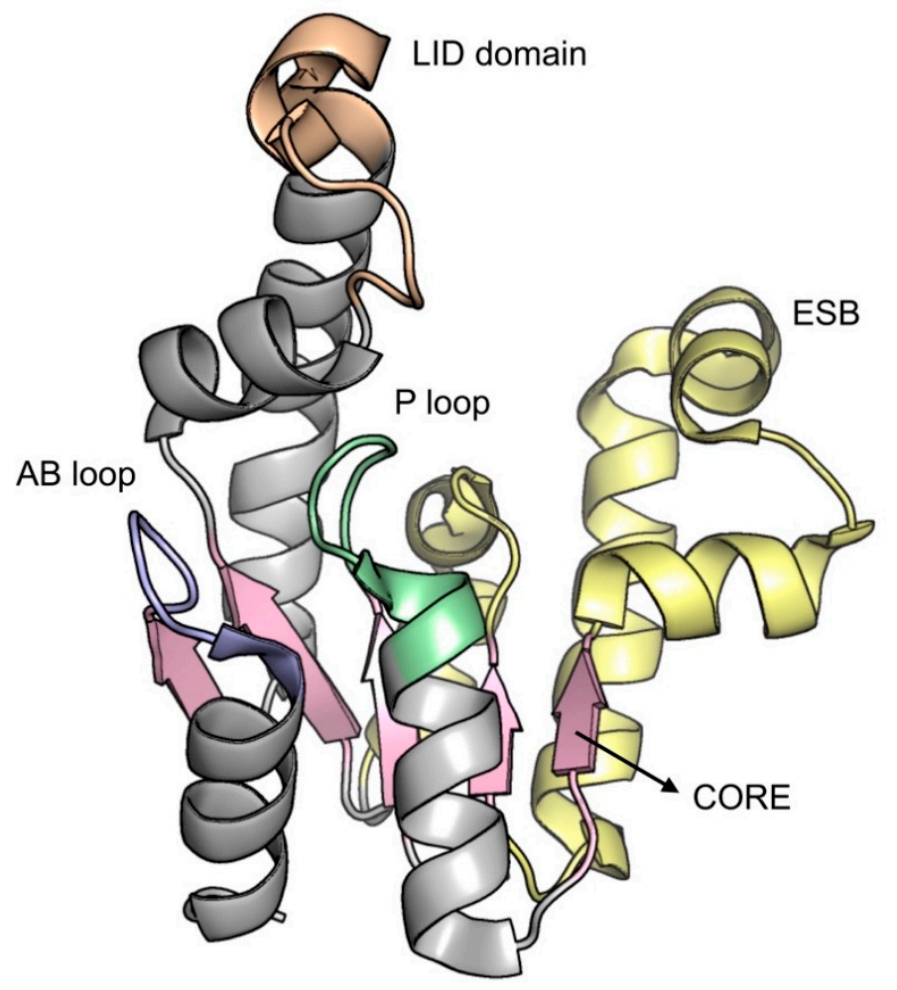

Figure 11. Overall MtSK structure. The image was generated on PyMOL.

Based on crystallographic studies, Hartmann and coworkers [115] described two distinct conformational states for MtSK-open and closed. In the open conformation (open LID), SHK or ATP can bind to the enzyme independently, thereby inducing LID closure. SHK has the same orientation in all complexes with $M t \mathrm{SK}$. The SHK binding site is characterized by a surface, usually hydrophobic, with some residues that align into the cavity. Pro11, Phe49, Phe57, Gly79, Gly80, Gly81, Pro118 and Leu119 form a lipophilic part of the pocket. The carboxylate group of SHK is anchored by a salt bridge with the guanidinium group of Arg136 and the side chain of Asp34 forms a bidentate hydrogen bond with the O12 hydroxyl group of SHK. 
Kinetic studies of fluorescence quenching on E. chrysanthemi SKII demonstrated that the binding of the first substrate (nucleotide) enhanced the affinity for SHK as second substrate [124]. Based on steady-state kinetics, fluorescence spectroscopy and isothermal titration calorimetry data for monomeric $\mathrm{MtSK}$, it was suggested that this enzyme follows a rapid-equilibrium random order of substrate binding (SHK or ATP) and ordered product release, in which S3P is released first, followed by ADP dissociation (Figure 12) [125]. Hartmann and coworkers [115] identified conformational changes in MtSK complexes that suggest synergic effects in the random sequential binding of SHK and ADP.

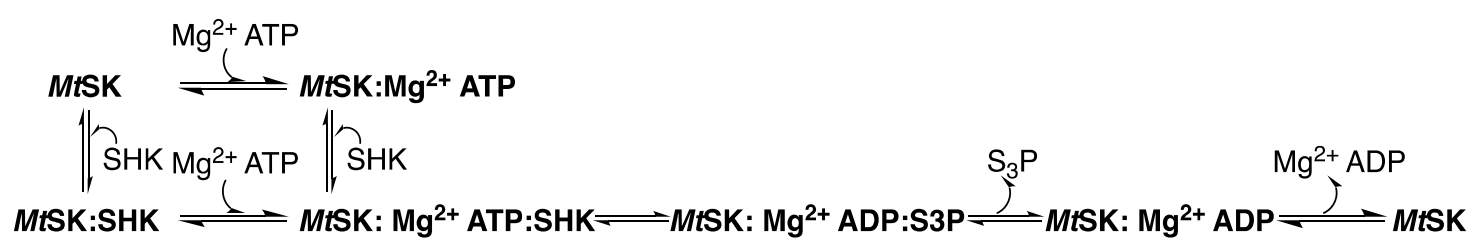

Figure 12. The kinetic mechanism of MtSK.

Experimental and computational studies have shown that catalysis may occur under specific conditions. The LID and SB domains are tightly closed presenting two possible arrangement: (a) the guanidinium group of the essential arginine, located in the LID domain, is close of the $\gamma$-phosphate of ATP for its activation and (b) the two substrates are very close together but isolated from the solvent environment for the reaction. The release of products requires a large conformational change involving the LID and SB domains, where the hydrogen bonds amongst the essential arginines (Arg117, Arg136 and Arg58) and the products need to be disrupted to release S3P [117,126].

$\mathrm{MtSK}$ is an interesting target for the development of inhibitors, since its function is essential for the survival of $M$. tuberculosis [31]. Different researches have been making efforts to find a potent molecule against this enzyme, which could help in the treatment of TB. Recently, six new compounds were characterized as MtSK inhibitors-manzamine A, 8-hydroxymanzamine A, manzamine E, manzamine F, 6-deoxymanzamine $X$ and 6-cyclohexamidomanzamine A. Inhibition studies demonstrated that these molecules show a mixed noncompetitive type of inhibition [127]. Another study showed a collection of 14 hits (out of 404 compounds) containing oxadiazole-amide and aminobenzothiazole scaffolds, which displayed $>90 \%$ inhibition at concentrations below $50 \mu \mathrm{M}$ against MtSK [123,128]. Compounds with aromatic modifications at the $\mathrm{C} 5$ hydroxyl group of shikimic acid present different inhibition constants against the MtSK and H. pylori SK (HpSK). The most potent inhibitor, with an O-benzyl moiety, showed $K_{\mathrm{i}}$ values of $10 \mu \mathrm{M}$ and $460 \mathrm{nM}$ against $\mathrm{MtSK}$ and HpSK, respectively [126]. Rajput and coworkers [129] identified 20 inhibitors, amongst which 5 showed $\mathrm{IC}_{50}$ values below $10 \mu \mathrm{M}$. The best molecule in the series exhibited an $\mathrm{IC}_{50}$ value of $5.1 \mu \mathrm{M}$, non-toxic $(\mathrm{SI}>10)$ in vitro cytotoxicity against HepG2 cell line and mitochondrial toxicity; synergistic with rifampicin and bactericidal against M. tuberculosis (MIC and Minimum bactericidal concentration of $4 \mu \mathrm{g} / \mathrm{mL}$ each) (Figure 13). Given the promising results for inhibitors of MtSK and the enzyme's essentiality in the survival of the TB bacillus, more effort should be made on the research of such an attractive target for the development of potential new molecules acting against TB. 
(a)<smiles>Cc1ccc(-c2nnc(NC(=O)c3ccccc3Cl)o2)c(C)c1</smiles>

$\mathrm{IC}_{50}=36 \mu \mathrm{M}$<smiles>CSc1ccc2nc(Nc3nc4ccccc4s3)sc2c1</smiles>

(b)<smiles>O=C(O)C1C[C@]2(O)C=CC(OC2)[C@H]1O</smiles><smiles>N[C@H]1C=C(C(=O)O)C[C@H](O)[C@@H]1O</smiles><smiles>N[C@H]1C=C(C(=O)O)C[C@H](O)[C@H]1O</smiles>

$K_{\mathrm{i}}=46 \mu \mathrm{M}$

$K_{\mathrm{i}}=62 \mu \mathrm{M}$

$K_{\mathrm{i}}=65 \mu \mathrm{M}$

(c)<smiles>C=C[C@H](O)[C@@H](O)C(C)C</smiles>

(d)<smiles>O=C(O)C1=CC(O)C(O)C(OCc2cccc([N+](=O)[O-])c2)C1</smiles>

Figure 13. Chemical structures of the top scoring compounds inhibiting MtSK identified from different studies. (a) [123,128]; (b) [117]; (c) [129]; (d) [126].

\subsection{5-Enolpyruvylshikimate-3-Phosphate Synthase (aroA Coding Sequence; EC 2.5.1.19)}

The enzyme 5-enolpyruvylshikimate-3-phosphate synthase from M. tuberculosis (MtEPSPS), responsible for the penultimate step in the shikimate pathway (Figure 1), is encoded by the aro $A$ sequence [130]. The cloning, recombinant expression and (one-step) purification protocols, as well as mass spectrometry analysis and N-terminal sequencing have been reported [130,131]. It has a molecular mass of 47,184 Da and belongs to the enolpyruvyl transferase family that does not require cofactors or metals for catalysis [132].

$X$-ray diffraction data at $1.81 \AA$ resolution (PDB 2O0E; Figure 14) showed that this monomeric enzyme is an $\alpha / \beta$ protein consisting of a mixed $\beta$-sheet surrounded by $\alpha$-helices. It is shaped by two domains and with the catalytic/active site near the interdomain crossover segment. Each domain is composed of three copies of a $\beta \alpha \beta \alpha \beta \beta$ folding unit, with a particular $\beta$-sheet in the fourth-strand, which contains parallel and antiparallel strands and all the $\alpha$-helices are parallel [132-134]. 


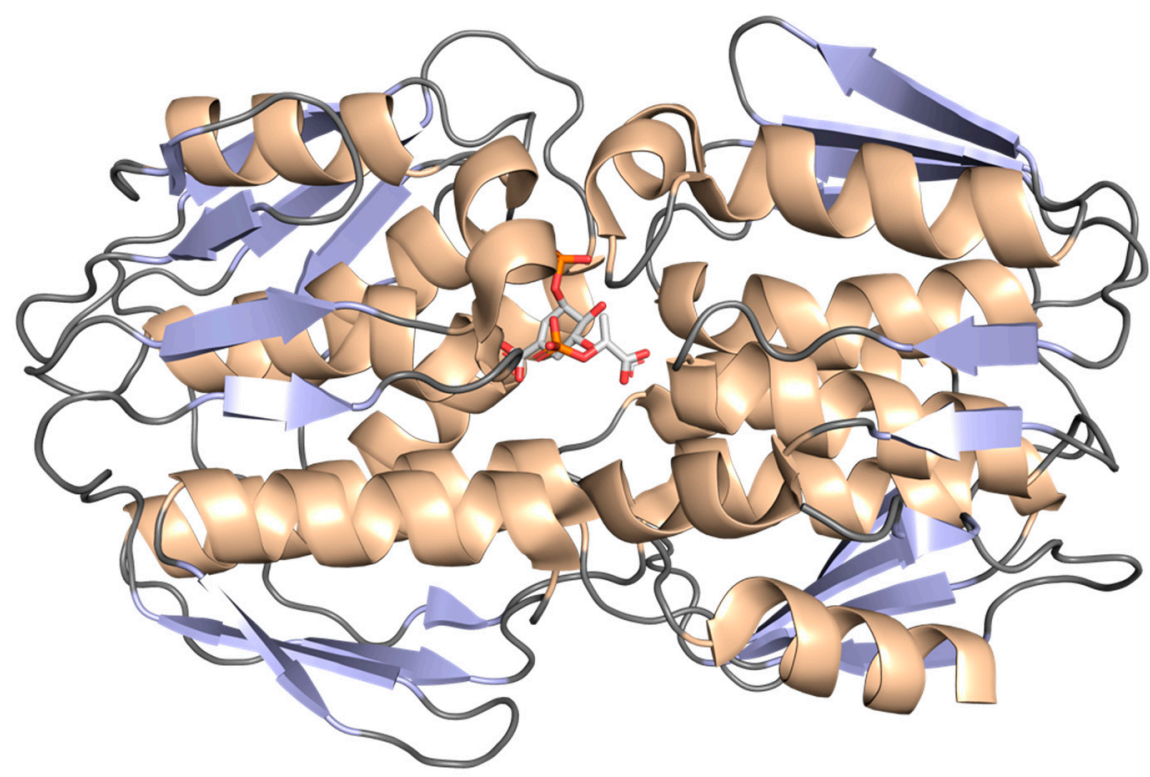

Figure 14. Graphical representation of MtEPSPS tertiary structure in complex with S3P and PEP. The image was generated on PyMOL.

Stallings and coworkers [135] deciphered the structure and topological symmetry of the E. coli enzyme. They found that each two-domain structure is composed of 6-folding protein units, each one being formed by four-stranded sheets and two parallel $\alpha$-helices. It was also found that the symmetry and orientation of the two domains make a direct effect on the binding of substrates and inhibitors by a helix macrodipole in MtEPSPS enzyme [133,134].

The catalytic mechanism of MtEPSPS involves the transfer of the enolpyruvyl moiety of PEP to the O5 of S3P [136], through an addition-elimination mechanism. Regarding the addition, it consists on PEP activation by $\mathrm{C} 3$ protonation associated with a nucleophilic attack on $\mathrm{C} 2$ with a tetrahedral reaction intermediate (THI) that (for a phosphate elimination) leads to a cationic intermediate and finally to 5-enolpyruvylshikimate-3-phosphate (EPSP) (Figure 15) [136-138].

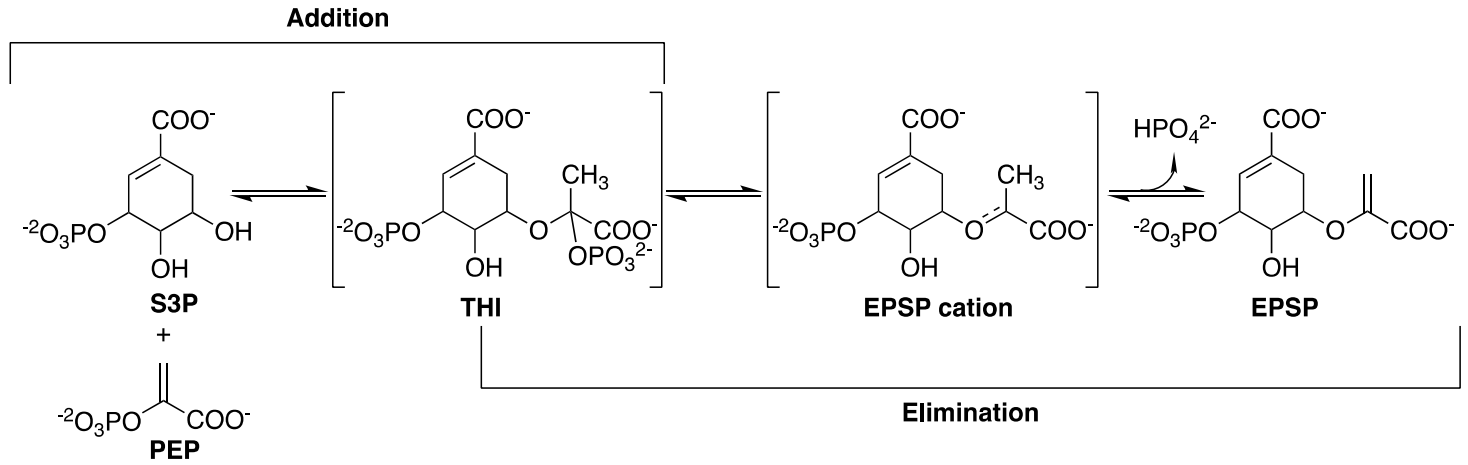

Figure 15. General reaction of EPSPS with the particular tetrahedral intermediate.

Lou and coworkers [138] studied the transition-state for the enzyme-catalyzed hydrolysis reaction measuring kinetic isotope effects. Based on these studies, three possible mechanisms were suggested for EPSP hydrolysis to form S3P and pyruvate catalyzed by E. coli EPSPS (assuming that the mechanisms for enzyme-catalyzed hydrolysis are the same as for the acid-catalyzed reaction), in which the reaction could start with: (a) $\mathrm{C} 3$ of PEP protonation in a stepwise $\mathrm{A}_{\mathrm{H}}{ }^{*} \mathrm{~A}_{\mathrm{N}}$ mechanism (proton and nucleophile addition occurring in distinct steps with a short-lived cationic intermediate that diffusionally equilibrates with solvent), (b) concerted C3 of PEP protonation and nucleophilic attack on $\mathrm{C} 2\left(\mathrm{~A}_{\mathrm{N}} \mathrm{A}_{\mathrm{H}}\right.$ : nucleophile and 
proton addition occurring simultaneously) or (c) nonactivated nucleophilic attack at C2 in a stepwise $\mathrm{A}_{\mathrm{N}}{ }^{*} \mathrm{~A}_{\mathrm{H}}$ mechanism. Hybrid quantum mechanical/molecular mechanical studies for E. coli EPSPS [139] suggest a stepwise mechanism in which protonation of PEP C3 by Glu341 precedes the nucleophilic attack on PEP C2 in the addition mechanism; the breaking of C-O bond of THI to release $\mathrm{HPO}_{4}{ }^{2-}$ and form the EPSP cation intermediate occurs before proton transfer from PEP C3 to Glu341 (acid/base enzyme catalyst) in the elimination mechanism to form the EPSP product (Figure 16).

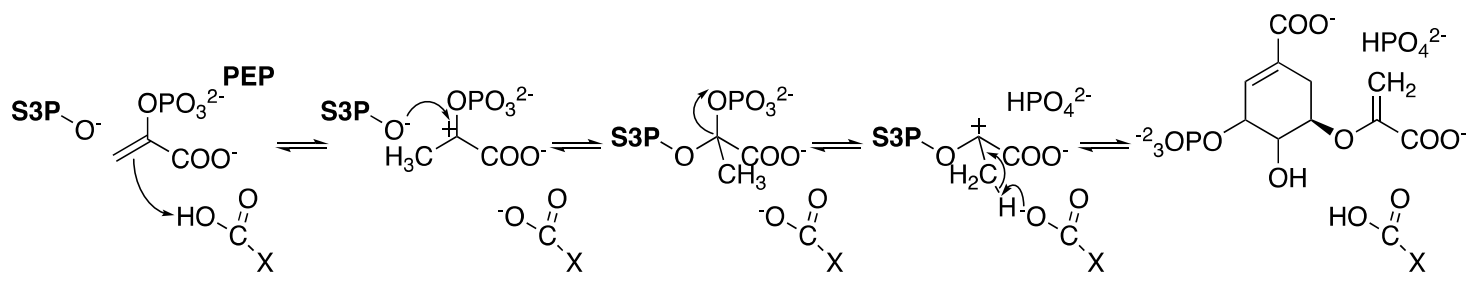

Figure 16. Scheme of the proposed mechanism of catalysis for EPSPS [139].

EPSPS is the cellular target of $N$-[phosphonomethyl] glycine, the active ingredient of the broad-spectrum, nonselective herbicide glyphosate [140]. The binding of glyphosate to MtEPSPS results in rearrangements of the enzyme's secondary structure, which are accompanied by a large decrease in solvent access to different regions of the protein [134]. A mechanism for MtEPSPS inhibition by glyphosate was proposed in which inhibitor-induced conformational changes cause a synergistic effect in preventing solvent access to the enzyme's active site. MtEPSPS exists in an open conformation in the apo form but in a closed conformation when bound to PEP. These conformations were studied by assessing the hydrogen/deuterium exchange properties of free MtEPSPS and MtEPSPS-PEP binary complex using electrospray ionization mass spectrometry (ESI-MS). The enzyme undergoes extensive conformational change upon formation of the PEP binary complex, which seems to favor solvent access at domain 1, while they partially prevent solvent access to domain 2 . This may be part of the mechanism of catalysis of the enzyme, which favors both hydration of the substrate-binding site in domain 1 (stabilizing S3P binding) and inducing cleft closure (which controls the entrance of substrate molecules) [132].

Multiple strains resistant to glyphosate were identified not long after the compound's inhibitory activity was demonstrated in plants $[140,141]$. Examples in prokaryotes include E. coli, in which G96A and A183T mutations in the enzyme rendered the bacteria insensitive to glyphosate [142]. In 2013, Ramachandran and coworkers [143] studied the inhibition of EPSPS in E. coli and M. tuberculosis with glyphosate, observing that the inhibition values for $M t$ EPSPS were about two orders of magnitude higher $\left(\mathrm{IC}_{50}=260 \mu \mathrm{M}\right)$ than for the $E$. coli ortholog $(3 \mu \mathrm{M})$, suggesting a lower affinity for the mycobacterial enzyme.

The importance of glyphosate in the study of this enzyme has been remarkable; based on the structure of this molecule, hundreds of analogue compounds were developed as candidates to inhibit this protein [139]. Studies proved the capacity of the enzyme to change its natural conformation in the presence of different analogues of glyphosate. Based on that, it was understood that EPSPS could change between open and closed conformations, which seems to be characterized by a decrease in the percentage of $\beta$-sheets and increase of the percentage of $\alpha$-helices [134].

The effects of inorganic phosphate (a product of the reaction) binding to MtEPSPS were assessed by analytical ultracentrifugation, small angle X-ray scattering and circular dichroism techniques, showing that MtEPSPS is in a closed conformation in the presence of inorganic phosphate and in an open conformation in the absence of inorganic phosphate [144]. Replica-exchange metadynamics simulations were employed to assess the effect of structural flexibility on MtEPSPS enzyme function [145]. The authors concluded that these results point to a classical model of conformational selection, in which apo MtEPSPS adopts a conformation that can bind strongly to a ligand and, on the other hand, ligand binding does not induce the enzyme to adopt an appropriate conformation for binding. This structural 
flexibility is important as a mechanism to adapt to different types of ligands and may be part of the rapid interconversion between different conformations of this protein through the rearrangement of the secondary structure. For example, the enzyme requires the complexation of three water molecules to stabilize the S3P into the binding site [134]. However, the available crystal structure for apo MtEPSPS (PDB 2BJB; manuscript to be published) is likely not the best representative of the conformational states of free enzyme present in solution, because the restricted condition of the crystal generation could produce a flexibility reduction, trapping the protein in a particular state, not in the natural solution state [145].

Numerous compounds that inhibit EPSPS have been proposed for different bacteria, such as E. coli, S. aureus and Bacillus cereus $[136,146,147]$. Although the sequence similarity between these organisms and M. tuberculosis varies between 21-28\%, none of these molecules have been tested in MtEPSPS. Kinetic and computational studies are necessary in order to evaluate the susceptibility of MtEPSPS to those compounds.

\subsection{Chorismate Synthase (aroF Coding Sequence; EC 4.2.3.5)}

Chorismate synthase from $M$. tuberculosis ( $M t C S$ ), the seventh and last enzyme in the shikimate pathway (Figure 1), is encoded by the aroF (Rv2540c) gene. This protein has a molecular mass of $41,804 \mathrm{Da}[148,149]$ and belongs to the family of carbon-oxygen lyases. The MtCS structure was determined by X-ray diffraction at $1.72 \AA$ resolution in complex with flavin mononucleotide (FMN) (PDB 2O12) (Figure 17). MtCS is a tetramer composed of two dimers (dimer of dimers) and the monomers belong to the structural $\alpha / \beta$ class, each monomer containing $13 \alpha$-helices and $17 \beta$-sheets and each of them is in contact with the others creating an intricate packing arrangement shaping a core domain composed of a topology of $\beta-\alpha-\beta$ sandwich, shown in Figure $17[150,151]$.

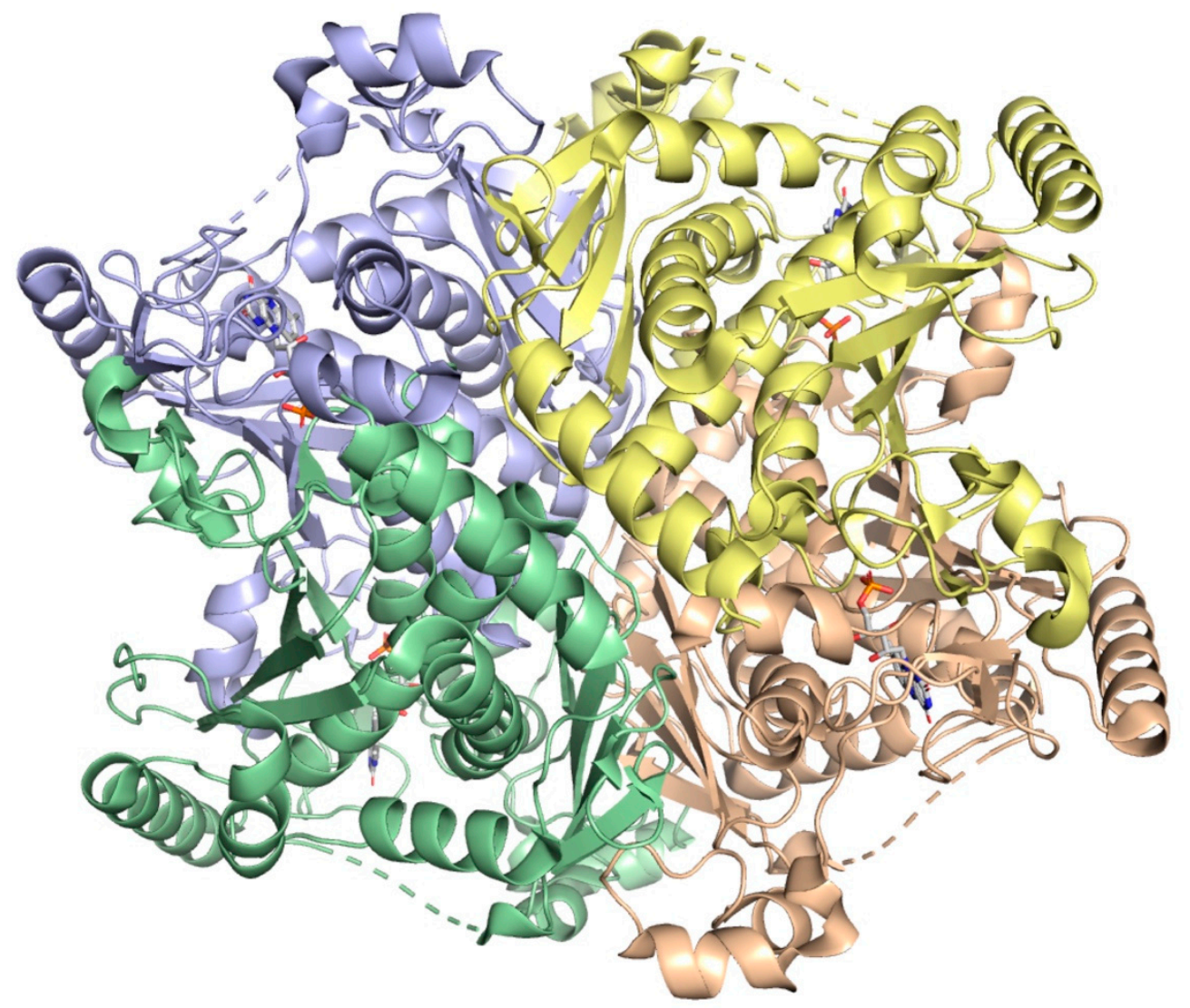

Figure 17. Graphical representation MtCS quaternary structure. The image was generated on PyMOL. 
MtCS catalyzes an unusual 1,4-anti-elimination of the 3-phosphate group and the C-(6proR) hydrogen from EPSP forming chorismate and phosphate [150,151]. Circular dichroism spectroscopy, gel filtration and analytical ultracentrifugation results suggest that MtCS exists in a dimer-tetramer equilibrium with a large value for the dissociation constant $(50 \mathrm{M})$, indicating that the enzyme is predominantly in the dimeric form in solution [150].

An interesting feature of CS from different organisms is how reduced FMN (FMN $\left.\mathrm{Fed}_{\text {red }}\right)$ is obtained, which divides these enzymes into two classes-monofunctional and bifunctional [152]. The CS enzymes from fungi are bifunctional as they display a second enzymatic activity, an NAD(P)H-dependent flavin reductase, which confers them an intrinsic ability to reduce flavin using $\mathrm{NAD}(\mathrm{P}) \mathrm{H}$. The CS enzymes from plants and E. coli are monofunctional as they do not possess this activity and are active only in anaerobic conditions in the presence of either chemically or enzymatically reduced flavin. Data on molecular cloning of aroF-encoded $\mathrm{MtCS}$, heterologous protein expression and purification, N-terminal amino acid sequencing and mass spectrometry of the recombinant protein indicate the bifunctionality of dimeric MtCS [149].

The enzyme's flavin reductase activity was characterized, showing the existence of a complex between $\mathrm{FMN}_{\mathrm{ox}}$ and MtCS. Equilibrium binding of $\mathrm{FMN}_{\mathrm{ox}}$ pointed to an upper limit of $20 \mu \mathrm{M}$ for the dissociation constant. NADH binding to $M t C S$ results in a quench in protein fluorescence and a value of $156 \mu \mathrm{M}$ was obtained for the dissociation constant for binary complex formation. Furthermore, solvent isotope effects and proton inventory results indicated that proton transfer from solvent partially limits the rate of FMN reduction and that a single proton transfer gives rise to the observed solvent isotope effect. Multiple isotope effects suggested a stepwise mechanism for the reduction of $\mathrm{FMN}_{\mathrm{ox}}$ (distinct steps for hydride and proton transfers) [149].

A new discontinuous method for measuring CS activity has been proposed to be applicable to both monofunctional (anaerobic) and bifunctional (aerobic) enzymes [153]. In short, the method is comprised of in situ production of EPSP by recombinant MtEPSPS, ultrafiltration, addition of FMN, $\mathrm{NADH}$ and recombinant $\mathrm{MtCS}$, filtration and detection of chorismate by liquid chromatography coupled with negative electrospray ionization high-resolution tandem mass spectrometry (ESI-HRMS). Although this method allows for determination of activity of a variety of CS enzymes, it would be somewhat difficult to be applicable to the identification of enzyme inhibitors in screening efforts of chemical compound libraries. Structural comparisons of MtCS and other CS enzymes performed by Arcuri and coworkers [151] found that conserved residues (such as His17 and His106) in the active binding site of the bifunctional enzyme are highly conserved amongst the species due to the fact that His106 is near C(2)_O of the Flavin ring and because His17 is near the phosphate group of EPSP, which could probably assist the protonation of the leaving group upon cleavage of C-O bond.

Numerous mechanisms have been proposed to explain the enzymatic reaction that converts EPSP into chorismate [154]. Nevertheless, a three-step mechanism for the CS reaction has been proposed based on quantum mechanics calculations combined with molecular mechanics (QM/MM) [155]. Considering that this reaction has an unusual stereochemistry of the trans-1,4-elimination of phosphate, having a proton involved in a non-concerted reaction and a cleavage of an inactivated $\mathrm{C}-\mathrm{H}$ bond, the mechanism starts with a proton transfer of $\mathrm{FMNH}_{2}$ to $\mathrm{D} 339$ ( $\mathrm{R}_{\mathrm{H} 3}$ transfer), followed by a proton transfer to FMNH ( $\mathrm{R}_{\mathrm{H} 8}$ transfer) from EPSP and finally the elimination of phosphate ( $\mathrm{R}_{\mathrm{PO}}$ elimination), as shown in Figure 18 [155,156]. 


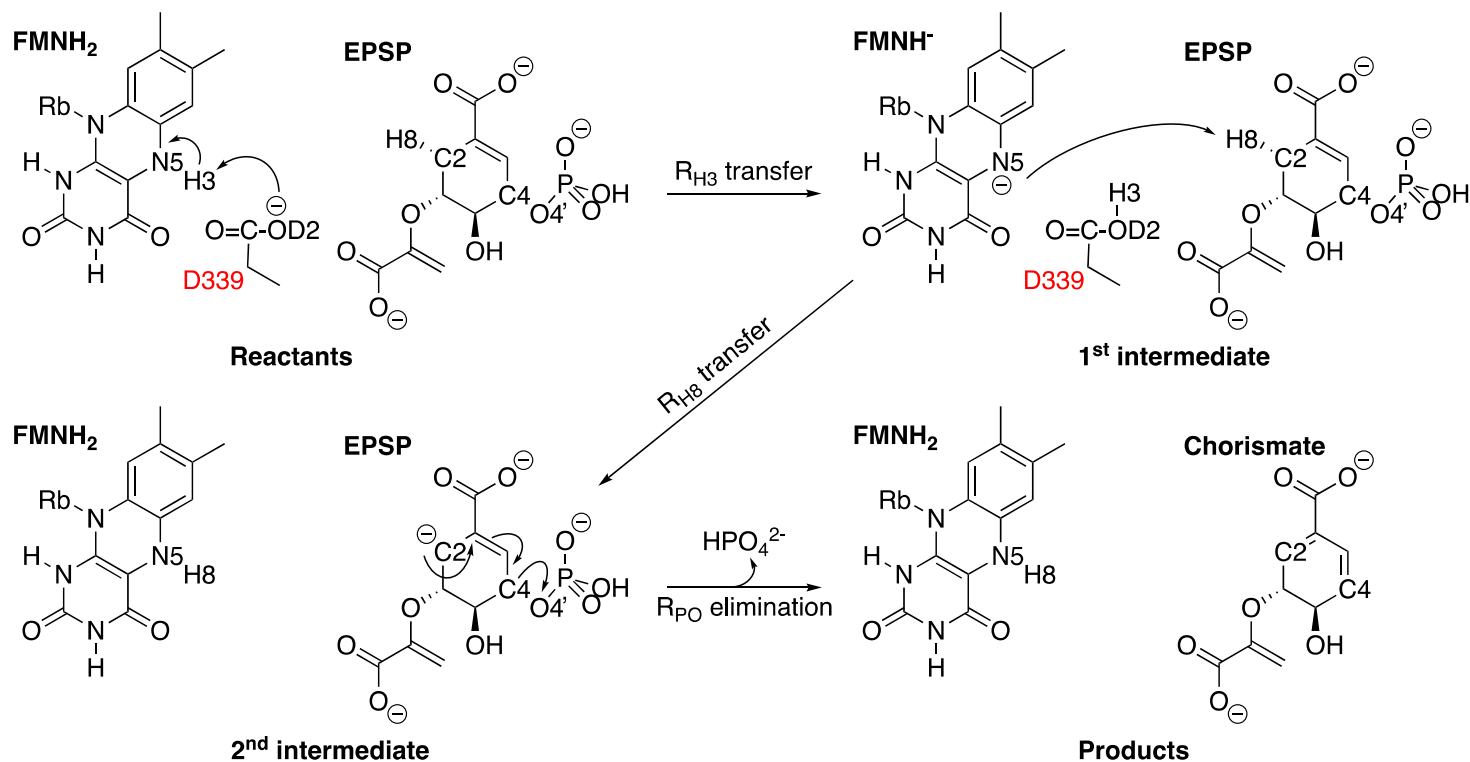

Figure 18. Proposed catalytic mechanism for the CS reaction based on quantum mechanics/molecular mechanics (QM/MM) with the interaction of aspartic acid 339 (D339).

The importance of a deeper understanding of chemical mechanisms is that, based on the structure of some important steps of the reaction, it is possible to developed analogues that can act as competitive or non-competitive inhibitors of the enzyme, blocking catalysis and preventing the formation of the product (chorismate), which is an essential precursor of aromatic amino acids, mycobactins, menaquinones and naphthoquinones. Some strategies based on these studies have proposed analogues, such as (6S)-6-fluoro shikimate, (6R)-6-fluoro shikimate, (6S)-6-fluoro EPSP and 2-(3-(3-((R)-3-((S)-1-Amino-3-(3-chlorophenyl)-1-oxopropan-2-ylamino)-2-(3-hydroxy-4-methyl-2nitrobenzamido)-3-oxopropylthio) propylcarbamoyl)phenoxy) acetic acid and other analogues of flavin, such as 2(Z)-2-benzylidene-6,7-dihydroxybenzofuran-3[2H]-ones and the 2'-hydroxy-4'-pentoxy, which inhibited the activity of bifunctional CS enzymes, such as N. crassa, Plasmodium falciparum, Salmonella typhimurium and Streptococcus pneumoniae [157,158].

To date, no publication has presented a single compound with an inhibitory capacity against MtCS. In 2007, Fernandes and coworkers [159] compared the three-dimensional structure and the geometric docking of the coenzyme FMN and the substrate EPSP amongst A. aeolicus, S. cerevisiae, H. pylori and S. pneumoniae (as a model of $M$. tuberculosis) and identified new possible interactions involving Arg111, Gly113 and Ser317 with the EPSP substrate. Since the structure of MtCS was determined a couple of months after this publication, the published analysis did not consider the actual structure of MtCS. For this reason, it is important to rationally develop compounds capable of interfering with Arg111, Gly113 and Ser317 and test them against the enzyme and the organism.

\section{Future Prospects}

The shikimate pathway is essential for the survival of mycobacteria [31]. Given the fact that this metabolic pathway is absent in humans, a better understanding of its component enzymes in M. tuberculosis and their chemical mechanisms of action, as well as their three-dimensional structures, should provide a framework on which to base the rational design of selective antimycobacterial agents. Overall, some advances were achieved within the last decade considering the shikimate pathway. Promising inhibitors were developed for some of these enzymes, with attractive MIC values and data on pharmacokinetic properties. This may give one a glimpse on what can be expected as we advance further into drug development. Although not necessarily applicable to the mycobacterial shikimate 
pathway, a combination with recent and alternative strategies could be explored beyond the ones presented above to target TB.

A multichannel device (iChip), which can simultaneously isolate and grow uncultured soil bacteria, was employed to identify teixobactin, which showed inhibition of $M$. tuberculosis in vitro growth; no drug-resistant strains could be selected [160]. Teixobactin blocks cell wall biosynthesis by binding to peptidoglycan precursors-lipid II (precursor for peptidoglycan biosynthesis) and lipid III (precursor for wall teichoic acid biosynthesis). Its interactions with decaprenyl-coupled lipid intermediates of peptidoglycan and arabinogalactan and its binding to wall teichoic acid precursor contributes to efficient lysis and killing due to digestion of the cell wall by liberated autolysins [160]. It has been pointed out that scale-up synthesis and cost-effective protocols of synthetic teixobactins, a better understanding of its pharmacokinetic properties, extensive in vivo evaluation of efficacy and toxicity and increased barrier to resistance could provide a robust platform for developing a new class of antibiotics for combatting multidrug-resistant bacterial infections [161]. The iChip platform grows and cultures bacteria within a natural environment, in which a soil sample from the environment is sandwiched between two semipermeable membranes and the sample is returned to the environment a short time later. As only approximately $1 \%$ of the billions of bacterial species in nature will grow in the lab, the iChip platform can unveil new natural compounds with antibacterial activity.

Cloudbreak is an antibody-drug conjugate platform that combines surface-acting antimicrobial agents with immune engagers in a single molecule that is developed by Cidara Therapeutics (www.cidara.com). The immune system is targeted by stably fusing multiple copies of the antimicrobial agent to the Fc domain of the human IgG1 antibody. The antimicrobial agents are engineered to target conserved regions of the pathogen where mutations often incur major fitness costs. Notwithstanding, the Cloudbreak platform has been used to develop antiviral Fc-conjugates (AVCs) against influenza and, moreover, reports for the development of antibacterials based on this platform are still lacking.

Extracellular M. tuberculosis in human TB lesions form biofilms (pellicles) in which the high cell density, cell-cell contacts and different nutrient and oxygen gradients within their interiors result in unique phenotypes, including drug tolerance [162]. A modified version of the culture-based hypoxia model in airtight containers (a phase in which drug-tolerant bacilli evolved) followed by aeration of cell cultures resulted in formation of a pellicle biofilm at the air-liquid interface. Flentie and coworkers [163] identified $R$-8-cyclopropyl-7-(naphthalen-1-ylmethyl)-5-oxo-3,5-dihydro-2H-thiazolo [3,2-a]pyridine-3-carboxylic acid, which inhibited hypoxia-induced tolerance to isoniazid (INH) in M. tuberculosis, prevented selection of drug-resistant strains and reversed INH resistance in kat $G$ mutants. However, further efforts should be pursued to translate this chemical compound into a chemotherapeutic agent to treat TB infection in human hosts infected with INH-resistant strains of $M$. tuberculosis harboring katG mutations [164]. Although the elucidation of the mode of action of this chemical compound may unveil novel targets that can be valuable for the development of new chemotherapeutic agents to treat $\mathrm{TB}$, it has limited therapeutic scope at the present time.

Host-directed therapies have emerged as a novel and promising approach to treat $\mathrm{TB}$, whose modulation of host response is likely to avoid the development of bacterial resistance $[165,166]$. Unlike conventional antibiotics aimed at targeting the bacteria, host-directed therapy aims at targeting the host immune response either by directly boosting its ability to effectively eliminate the bacterial load or reduce the lung damage associated with granulomatous disease. This strategy has the advantage that molecules would be active against infections taking shelter in the host immune cells and are difficult to target and so might be able to shorten treatment regimens or be effective for individuals with latent TB. Host-directed therapy may be regarded as an adjunct TB therapy to improve the clearance achieved by antibiotics in M. tuberculosis.

A new strategy termed PROSPECT (primary screening of strains to prioritize expanded chemistry and targets) was developed in which large chemical libraries (50,000 compounds) are screened against pools of mutant strains depleted in essential bacterial targets (100-150 hypomorphs) and their 
hypersensitivity are exploited to generate large-scale chemical-genetic interaction profiles (CGIPs). The PROSPECT strategy simultaneously identifies whole-cell active compounds and predicts their mode of action from the primary screening data, which provides putative target information that can help guide hit prioritization [167]. Moreover, a larger target space and new chemical scaffolds may be unveiled by this strategy as compared to whole-cell screening. Using primary CGIPs, it was possible to identify and validate more than 40 new scaffolds against established targets including DNA gyrase, RNA polymerase and the biosynthesis of mycolic acids, folate, tryptophan and the new essential efflux pump EfpA target. Johnson and coworkers [167] have made primary data publicly available (https://broad.io/cgtb) to, in their words, accelerate the discovery of new inhibitor chemotypes and their targets.

In this section we have attempted to give a broad view of expanding experimental strategies to devise new therapies to treat TB. There is also an increased need for expanding the variety and complexity of cell-based assays for biological research and drug discovery. Stem cell-derived cells and tissues have become an increasingly attractive alternative to traditional in vitro and in vivo testing in pharmaceutical drug development and toxicological safety assessment. The Japanese Global Health Innovative Technology Fund proposed a set of criteria for hits and leads identified in screening campaigns of chemical compounds to treat neglected tropical diseases, including TB [168]. These criteria provide clear guidelines for decisions on whether progress from hit to lead and then on into lead optimization. To wrap it up, the concept of focusing on science was exemplified recently when AstraZeneca published a framework founded on project quality and depth of understanding as a

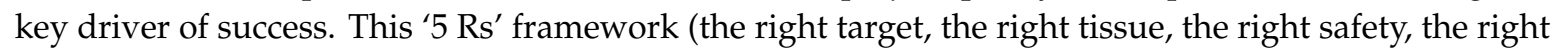
patient and the right commercial potential) can be modified to encompass the influence of mechanistic enzymology in the early stages of drug discovery — right target + right reagents + right assay + right mechanism $=$ right compound [15].

Author Contributions: All authors have read and agree to the published version of the manuscript. ${ }^{\dagger}$ J.E.S.N. and M.A.D. are equal-contributing first authors. Writing - Original Draft Preparation: J.E.S.N., M.A.D., T.F.F., L.G., L.F.S.M.T., C.V.B, P.M., L.A.B. and R.G.D. Writing - Review \& Editing: L.A.B. and R.G.D.

Acknowledgments: C.V.B.: P.M. and L.A.B. would like to acknowledge financial support given by CNPq/FAPERGS/CAPES/BNDES to the National Institute of Science and Technology on Tuberculosis (INCT-TB), Brazil [grant numbers: 421703-2017-2/17-1265-8/14.2.0914.1). C.V.B. [310344/2016-6], P.M. [305203/2018-5) and L.A.B. [520182/99-5] are research career awardees of the National Council for Scientific and Technological Development of Brazil (CNPq). L.F.S.M.T is supported by grants 407537/2018-0 from CNPq and 10901360 from the Universidade do Vale do Taquari (Univates). This study was financed in part by the Coordenação de Aperfeiçoamento de Pessoal de Nível Superior-Brasil (CAPES)—Finance Code 001.

Conflicts of Interest: The authors declare no conflict of interest.

\section{References}

1. WHO. Global tuberculosis report 2019. 2019. Licence: CC BY-NC-SA 3.0 IGO. Available online: www.who. int/tb/publications/global_report/en (accessed on 27 December 2019).

2. Mandal, S.; Njikan, S.; Kumar, A.; Early, J.V.; Parish, T. The relevance of persisters in tuberculosis drug discovery. Microbiology 2019, 165, 492-499. [CrossRef] [PubMed]

3. Ducati, R.G.; Ruffino-Netto, A.; Basso, L.A.; Santos, D.S. The resumption of consumption-A review on tuberculosis. Mem. Inst. Oswaldo Cruz. 2006, 101, 697-714. [CrossRef] [PubMed]

4. Pang, Y.; Zhao, A.; Cohen, C.; Kang, W.; Lu, J.; Wang, G.; Zhao, Y.; Zheng, S. Current status of new tuberculosis vaccine in children. Hum. Vaccin. Immunother. 2016, 12, 960-970. [CrossRef] [PubMed]

5. Cole, S.T.; Brosch, R.; Parkhill, J.; Garnier, T.; Churcher, C.; Harris, D.; Gordon, S.V.; Eiglmeier, K.; Gas, S.; Barry, C.E., 3rd; et al. Deciphering the biology of Mycobacterium tuberculosis from the complete genome sequence. Nature 1998, 393, 537-544. [CrossRef]

6. Yuan, T.; Sampson, N.S. Hit generation in TB drug discovery: From genome to granuloma. Chem. Rev. 2018, 118, 1887-1916. [CrossRef] 
7. Wellington, S.; Hung, D.T. The expanding diversity of Mycobacterium tuberculosis drug targets. ACS Infect. Dis. 2018, 4, 696-714. [CrossRef]

8. Moffat, J.G.; Vincent, F.; Lee, J.A.; Eder, J.; Prunotto, M. Opportunities and challenges in phenotypic drug discovery: An industry perspective. Nat. Rev. Drug Discov. 2017, 16, 531-543. [CrossRef]

9. Comess, K.M.; McLoughlin, S.M.; Oyer, J.A.; Richardson, P.L.; Stöckmann, H.; Vasudevan, A.; Warder, S.E. Emerging approaches for the identification of protein targets of mall molecules-a practitioners' perspective. J. Med. Chem. 2018, 61, 8504-8535. [CrossRef]

10. Gajdács, M. The Concept of an Ideal Antibiotic: Implications for Drug Design. Molecules 2019, 24, E892. [CrossRef]

11. McNeil, M.B.; Cook, G.M. Utilization of CRISPR interference to validate MmpL3 as a drug target in Mycobacterium tuberculosis. Antimicrob. Agents Chemother. 2019, 63, e00629. [CrossRef]

12. Halgren, T.A. Identifying and characterizing binding sites and assessing druggability. J. Chem. Inf. Model. 2009, 49, 377-389. [CrossRef] [PubMed]

13. Gashaw, I.; Ellinghaus, P.; Sommer, A.; Asadullah, K. What makes a good drug target? Drug Discov. Today. 2011, 16, 1037-1043. [CrossRef] [PubMed]

14. Imming, P.; Sinning, C.; Meyer, A. Drugs, their targets and the nature and number of drug targets. Nat. Rev. Drug Discov. 2006, 5, 821-834. [CrossRef] [PubMed]

15. Holdgate, G.A.; Meek, T.D.; Grimley, R.L. Mechanistic enzymology in drug discovery: A fresh perspective. Nat. Rev. Drug Discov. 2018, 17, 115-132. [CrossRef]

16. Greenwood, D.J.; Santos, M.S.; Huang, S.; Russell, M.R.G.; Collinson, L.M.; McRae, J.I.; West, A.; Jiang, H.; Gutierrez, M.G. Subcellular antibiotic visualization reveals a dynamic drug reservoir in infected macrophages. Science 2019, 364, 1279-1282. [CrossRef]

17. Bentley, R. The shikimate pathway a metabolic tree with many branches. Crit. Rev. Biochem. Mol. Biol. 1990, 25, 307-384. [CrossRef]

18. Herrmann, K.M.; Weaver, L.M. The shikimate pathway. Annu. Rev. Plant. Physiol. Mol. Biol. 1999, 50, 473-503. [CrossRef]

19. Coggins, J.R.; Abell, C.; Evans, L.B.; Frederickson, M.; Robinson, D.A.; Roszak, A.W.; Lapthorn, A.P. Experiences with the shikimate-pathway enzymes as targets for rational drug design. Biochem. Soc. Trans. 2003, 31, 548-551. [CrossRef]

20. Roberts, F.; Roberts, C.W.; Johnson, J.J.; Kyle, D.E.; Krell, T.; Coggins, J.R.; Coombs, G.H.; Milhous, W.K.; Tzipori, S.; Fergunson, D.J.P.; et al. Evidence for shikimate pathway in apicomplexan parasites. Nature 1998, 393, 801-805. [CrossRef]

21. Ducati, R.G.; Basso, L.A.; Santos, D.S. Mycobacterial shikimate pathway enzymes as targets for drug design. Curr. Drug Targets. 2007, 8, 423-435. [CrossRef]

22. Mir, R.; Jallu, S.; Singh, T.P. The shikimate pathway: Review of amino acid sequence, function and three-dimensional structures of the enzymes. Crit. Rev. Microbiol. 2015, 41, 172-189. [CrossRef] [PubMed]

23. Zhang, Y.J.; Reddy, M.C.; Ioerger, T.R.; Rothchild, A.C.; Dartois, V.; Schuster, B.M.; Trauner, A.; Wallis, D.; Galaviz, S.; Huttenhower, C.; et al. Tryptophan biosynthesis protects mycobacteria from CD4 T-cell-mediated killing. Cell 2013, 155, 1296-1308. [CrossRef] [PubMed]

24. Herrmann, K.M.; Weaver, L.M. 3-Deoxy-D-arabino-heptulosonate 7-phosphate synthase. Purification, properties and kinetics of the tyrosine-sensitive isoenzyme from Escherichia coli. J. Biol. Chem. 1976, 251, 5440-5447.

25. Tzin, V.; Galili, G.; Aharoni, A. Shikimate Pathway and Aromatic Amino Acid Biosynthesis. eLS. John Wiley $\mathcal{E}$ Sons 2012.

26. Jiao, W.; Blackmore, N.J.; Nazmi, A.R.; Parker, E.J. Quaternary structure is an essential component that contributes to the sophisticated allosteric regulation mechanism in a key enzyme from Mycobacterium tuberculosis. PLoS ONE 2017, 12, 1-21. [CrossRef]

27. Jensen, R.A.; Xie, G..; Calhoun, D.H.; Bonner, C.A. The correct phylogenetic relationship of KdsA (3-deoxy-d-manno-octulosonate 8-phosphate synthase) with one of two independently evolved classes of AroA (3-deoxy-d-arabino-heptulosonate 7-phosphate synthase). J. Mol. Evol. 2002, 54, 416-423. [CrossRef]

28. Webby, C.J.; Baker, H.M.; Lott, J.S.; Baker, E.N.; Parker, E.J. The structure of 3-deoxy-D-arabino-heptulosonate 7-phosphate synthase from Mycobacterium tuberculosis reveals a common catalytic scaffold and ancestry for type I and type II enzymes. J. Mol. Biol. 2005, 354, 927-939. [CrossRef] 
29. Shumilin, I.A.; Kretsinger, R.H.; Bauerle, R.H. Crystal structure of phenylalanine-regulated 3-deoxy-D-arabino-heptulosonate-7-phosphate synthase from Escherichia coli. Structure 1999, 7, 865-875. [CrossRef]

30. Shumilin, I.A.; Zhao, C.; Bauerle, R.; Kretsinger, R.H. Allosteric inhibition of 3-deoxy-D-arabino-heptulosonate-7-phosphate synthase alters the coordination of both substrates. J. Mol. Biol. 2002, 320, 1147-1156. [CrossRef]

31. Parish, T.; Stoker, N.G. The common aromatic amino acid biosynthesis pathway is essential in Mycobacterium tuberculosis. Microbiology 2002, 148, 3069-3077. [CrossRef]

32. Furdui, C.; Zhou, L.; Woodard, R.W.; Anderson, K.S. Insights into the mechanism of 3-deoxy-D-arabino-heptulosonate 7-phosphate synthase (Phe) from Escherichia coli using a transient kinetic analysis. J. Biol. Chem. 2004, 279, 45618-45625. [CrossRef] [PubMed]

33. Sterritt, O.W.; Lang, E.J.M.; Kessans, S.A.; Ryan, T.M.; Demeler, B.; Jameson, G.B.; Parker, E.J. Structural and functional characterisation of the entry point to pyocyanin biosynthesis in Pseudomonas aeruginosa defines a new 3-deoxy-D-arabino-heptulosonate 7-phosphate synthase subclass. Bio. Sci. Rep. 2018, 38, BSR20181605. [CrossRef] [PubMed]

34. Webby, C.J.; Patchett, M.L.; Parker, E.J. Characterization of a recombinant type II 3-deoxy-D-arabino-heptulosonate-7-phosphate synthase from Helicobacter pylori. Bio. Chem. J. 2005, 390, 223-230. [CrossRef] [PubMed]

35. Reichau, S.; Jiao, W.; Walker, S.R.; Hutton, R.H.; Baker, E.N.; Parker, E.J. Potent inhibitors of a shikimate pathway enzyme from Mycobacterium tuberculosis: Combining mechanism- and modeling-based design. J. Bio. Chem. 2011, 286, 16197-16207. [CrossRef]

36. Webby, C.J.; Jiao, W.; Hutton, R.D.; Blackmore, N.J.; Baker, H.M.; Baker, E.N.; Jameson, G.B.; Parker, E.J. Synergistic allostery: A sophisticated regulatory network for the control of aromatic amino acid biosynthesis in Mycobacterium tuberculosis. J. Biol. Chem. 2010, 285, 30567-30576. [CrossRef]

37. Blackmore, N.J.; Reichau, S.; Jiao, W.; Hutton, R.D.; Baker, E.N.; Jameson, G.B.; Parker, E.J. Three sites and you are out: Ternary synergistic allostery controls aromatic amino acid biosynthesis in Mycobacterium tuberculosis. J. Mol. Biol. 2013, 425, 1582-1592. [CrossRef]

38. Munack, S.; Roderer, K.; Okvist, M.; Kamarauskaite, J.; Sasso, S.; van Eerde, A.; Kast, P.; Krengel, U. Remote control by inter-enzyme allostery: A novel paradigm for regulation of the shikimate pathway. J. Mol. Biol. 2016, 428, 1237-1255. [CrossRef]

39. Sterritt, O.W.; Kessans, S.A.; Jameson, G.B.; Parker, E.J. A Pseudoisostructural Type II DAH7PS Enzyme from Pseudomonas aeruginosa: Alternative Evolutionary Strategies to Control Shikimate Pathway Flux. Biochemistry 2018, 57, 2667-2678. [CrossRef]

40. Blackmore, N.J.; Nazmi, A.R.; Hutton, R.D.; Webby, M.N.; Baker, E.N.; Jameson, G.B.; Parker, E.J. Complex formation between two biosynthetic enzymes modifies the allosteric regulatory properties of both: An example of molecular symbiosis. J. Biol. Chem. 2015, 290, 18187-18198. [CrossRef]

41. Nirmal, C.R.; Rao, R.; Hopper, W. Inhibition of 3-deoxy-D-arabino-heptulosonate 7-phosphate synthase from Mycobacterium tuberculosis: In silico screening and in vitro validation. Eur. J. Med. Chem. 2015, 105, 182-193. [CrossRef] [PubMed]

42. Frost, J.W.; Bender, J.L.; Kadonaga, J.T.; Knowles, J.R. Dehydroquinate Synthase from Escherichia coli: Purification, Cloning and Construction of Overproducers of the Enzyme. Biochemistry 1984, 23, 4470-4475. [CrossRef] [PubMed]

43. Srinivasan, P.R.; Rothschild, J.; Sprinson, D.B. The Enzymic Conversion of 3-Deox-D-arabino-heptulosonic Acid 7-Phosphate to 5- Dehydroquinate. J. Biol. Chem. 1963, 238, 3176-3182. [PubMed]

44. Coggins, J.R.; Duncan, K.; Anton, I.A.; Boocock, M.R.; Chaudhuri, S.; Lambert, J.M.; Lewendon, A.; Millar, G.; Mousdale, D.M.; Smith, D.D.S. The anatomy of a multifunctional enzyme. Bio. Chem. Soc. Trans. 1987, 15, 754-759. [CrossRef] [PubMed]

45. Hawkins, A.R.; Lamb, H.K. The Molecular Biology of Multidomain Proteins Selected Examples. Eur. J. Biochem. 1995, 232, 7-18. [CrossRef]

46. Carpenter, E.P.; Hawkins, A.R.; Frost, J.W.; Brown, K.A. Structure of dehydroquinate synthase reveals an active site capable of multistep catalysis. Nature 1998, 394, 299-302. [CrossRef] [PubMed]

47. Bender, S.L.; Mehdi, S.; Knowles, J.R. Dehydroquinate Synthase: The Role of Divalent Metal Cations and of Nicotinamide Adenine Dinucleotide in Catalysis. Biochemistry 1989, 28, 7555-7560. [CrossRef] 
48. Widlanski, T.; Bender, S.L.; Knowles, J.R. Dehydroquinate Synthase: The Use of Substrate Analogues To Probe the Late Steps of the Catalyzed Reaction. Biochemistry 1989, 28, 7572-7582. [CrossRef]

49. De Mendonça, J.D.; Ely, F.; Palma, M.S.; Frazzon, J.; Basso, L.A.; Santos, D.S. Functional characterization by genetic complementation of aroB-encoded dehydroquinate synthase from Mycobacterium tuberculosis $\mathrm{H} 37 \mathrm{Rv}$ and its heterologous expression and purification. J. Bacteriol. 2007, 189, 6246-6252. [CrossRef]

50. De Mendonça, J.D.; Adachi, O.; Rosado, L.A.; Ducati, R.G.; Santos, D.S.; Basso, L.A. Kinetic mechanism determination and analysis of metal requirement of dehydroquinate synthase from Mycobacterium tuberculosis H37Rv: An essential step in the function-based rational design of anti-TB drugs. Mol. Biosyst. 2011, 7, 119-128. [CrossRef]

51. Moore, J.D.; Coggins, J.R.; Virden, R.; Hawkins, A.R. Efficient independent activity of a monomeric, monofunctional dehydroquinate synthase derived from the $\mathrm{N}$-terminus of the pentafunctional AROM protein of Aspergillus nidulans. Biochem. J. 1994, 301, 297-304. [CrossRef]

52. Skinner, M.A.; Günel-Ozcan, A.; Moore, J.; Hawkins, A.R.; Brown, K.A. Dehydroquinate Synthase Binds Divalent and Trivalent Cations: Role of Metal Binding in Catalysis. Biochem. Soc. Trans. 1997, $25, \mathrm{~S} 609$. [CrossRef] [PubMed]

53. Le Marechal, P.; Froussios, C.; Level, M.; Azerad, R. The Interaction of Phosphonate and Homophosphonate Analogues of 3-Deoxy-D-Arabino Heptulosonate 7-Phospate With 3-Dehydroquinate Synthase from Escherichia coli. Biochem. Biophys. Res. Commun. 1980, 92, 1104-1109. [CrossRef]

54. Zhu, N.; Wang, X.; Li, D.; Lin, Y.; You, X.; Jiang, J.; Xu, Y.; Jiang, W.; Si, S. IMB-T130 targets 3-dehydroquinate synthase and inhibits Mycobacterium tuberculosis. Sci. Rep. 2018, 8, 1-9. [CrossRef] [PubMed]

55. Zhu, N.; Lin, Y.; Li, D.; Gao, N.; Liu, C.; You, X.; Jiang, J.; Jiang, W.; Si, S. Identification of an anti-TB compound targeting the tyrosyl-tRNA synthetase. J. Antimicrob. Chemother. 2015, 70, 2287-2294. [CrossRef]

56. Mitsuhashi, S.; Davis, B.D. Aromatic biosynthesis. XII. Conversion of 5-dehydroquinic acid to 5-dehydroshikimic acid dy 5-dehydroquinase. Biochim. Biophys. Acta. - Gen. Subj. 1954, 15, 54-61.

57. Gourley, D.G.; Shrive, A.K.; Polikarpov, I.; Krell, T.; Coggins, J.R.; Hawkins, A.R.; Isaacs, N.W.; Sawyer, L. The two types of 3-dehydroquinase have distinct structures but catalyze the same overall reaction. Nat. Struct. Biol. 1999, 6, 521-525.

58. Garbe, T.; Servos, S.; Hawkins, A.; Dimitriadis, G.; Young, D.; Dougan, G.; Charles, I. The Mycobacterium tuberculosis shikimate pathway genes: Evolutionary relationship between biosynthetic and catabolic 3-dehydroquinases. MGG Mol. Gen. Genet. 1991, 228, 385-392. [CrossRef]

59. Kleanthous, C.; Deka, R.; Davis, K.; Kelly, S.M.; Cooper, A.; Harding, S.E.; Price, N.C.; Hawkins, A.R.; Coggins, J.R. A comparison of the enzymological and biophysical properties of two distinct classes of dehydroquinase enzymes. Biochem. J. 1992, 282, 687-695. [CrossRef]

60. Harris, J.; Kleanthous, C.; Coggins, J.R.; Hawkins, A.R.; Abell, C. Different Mechanistic and Stereochemical Courses for the Reactions catalysed by Type I and Type II Dehydroquinases. J. Chem. Soc. Chem. Commun. 1993, 13, 1080-1081. [CrossRef]

61. Roszak, A.W.; Robinson, D.A.; Krell, T.; Hunter, I.S.; Fredrickson, M.; Abell, C.; Coggins, J.R.; Lapthorn, A.J. The structure and mechanism of the type II dehydroquinase from Streptomyces coelicolor. Structure 2002, 10, 493-503. [CrossRef]

62. Turner, M.J.; Smith, B.W.; Haslam, E. The shikimate pathway. Part IV. The stereochemistry of the 3-dehydroquinate dehydratase reaction and observations on 3-dehydroquinate synthetase. J. Chem. Soc. Perkin Trans. 1975, 1, 52-55. [CrossRef]

63. Shneier, A.; Harris, J.; Kleanthous, C.; Coggins, J.R.; Hawkins, A.R.; Abell, C. Evidence for Opposite Stereochemical Courses for the Reactions Catalysed by Type I and Type II Dehydroquinases. Bioorganic Med. Chem. 1993, 3, 1399-1402. [CrossRef]

64. Le Sann, C.; Gower, M.A.; Abell, A.D. Inhibitors of Types I and II Dehydroquinase. Mini Rev. Med. Chem. 2004, 4, 747-756. [PubMed]

65. González-Bello, C.; Tizón, L.; Lence, E.; Otero, J.M.; Van Raaij, M.J.; Martinez-Guitian, M.; Beceiro, A.; Thompson, P.; Hawkins, A.R. Chemical Modification of a Dehydratase Enzyme Involved in Bacterial Virulence by an Ammonium Derivative: Evidence of its Active Site Covalent Adduct. J. Am. Chem. Soc. 2015, 137, 9333-9343. [CrossRef] 
66. Harris, J.M.; Gonzalez-bello, C.; Kleanthous, C.; Hawkins, A.R.; Coggins, J.R.; Abell, C. Evidence from kinetic isotope studies for an enolate intermediate in the mechanism of type II dehydroquinases. Biochem. J. 1996, 319, 333-336. [CrossRef]

67. Devi, A.S.; Ebihara, A.; Kuramitsu, S.; Yokoyama, S.; Kumarevel, T.; Ponnuraj, K. Crystal structure of type I 3-dehydroquinate dehydratase of Aquifex aeolicus suggests closing of active site flap is not essential for enzyme action. Biochem. Biophys. Res. Commun. 2013, 432, 350-354. [CrossRef]

68. Cheung, V.W.N.; Xue, B.; Hernandez-Valladares, M.; Go, M.K.; Tung, A.; Aguda, A.H.; Robinson, R.C.; Yew, W.S. Identification of polyketide inhibitors targeting 3-dehydroquinate dehydratase in the shikimate pathway of Enterococcus faecalis. PLoS ONE 2014, 9, 1-9. [CrossRef]

69. Petersen, G.O.; Saxena, S.; Renuka, J.; Soni, V.; Yogeeswari, P.; Santos, D.S.; Bizarro, C.V.; Sriram, D. Structure-based virtual screening as a tool for the identification of novel inhibitors against Mycobacterium tuberculosis 3-dehydroquinate dehydratase. J. Mol. Graph. Model. 2015, 60, 124-131. [CrossRef]

70. Lee, B.I.; Kwak, J.E.; Suh, S.W. Crystal structure of the type II 3-dehydroquinase from Helicobacter pylori. Proteins Struct. Funct. Genet. 2003, 51, 616-617. [CrossRef]

71. Iqbal, N.; Kumar, M.; Sharma, P.; Yadav, S.P.; Kaur, P.; Sharma, S.; Singh, T.P. Binding studies and structure determination of the recombinantly produced type-II 3-dehydroquinate dehydratase from Acinetobacter baumannii. Int. J. Biol. Macromol. 2017, 94, 459-465. [CrossRef]

72. Reiling, S.; Kelleher, A.; Matsumoto, M.M.; Robinson, G.; Asojo, O.A. Structure of type II dehydroquinase from Pseudomonas aeruginosa. Acta Crystallogr. Sect. F Structural Biol. Commun. 2014, 70, 1485-1491. [CrossRef]

73. Dias, M.V.B.; Blundell, T.L.; Snee, W.C.; Palaninathan, S.K.; Sacchettini, J.C.; Bromfield, K.M.; Payne, R.J.; Ciulli, A.; Howard, N.I.; Abell, C. Structural investigation of inhibitor designs targeting 3-dehydroquinate dehydratase from the shikimate pathway of Mycobacterium tuberculosis. Biochem. J. 2011, 436, 729-739. [CrossRef]

74. Krell, T.; Horsburght, M.J.; Cooper, A.; Kelly, S.M.; Coggins, J.R. Localization of the active site of type II dehydroquinases. Identification of a common arginine-containing motif in the two classes of dehydroquinases. J. Biol. Chem. 1996, 271, 24492-24497. [CrossRef] [PubMed]

75. Peón, A.; Otero, J.M.; Tizón, L.; Prazeres, V.F.V.; Llamas-Saiz, A.L.; Fox, G.C.; Van Raaij, M.J.; Lamb, H.; Hawkins, A.R.; Gago, F.; et al. Understanding the key factors that control the inhibition of type II dehydroquinase by (2R)-2-benzyl-3-dehydroquinic acids. ChemMedChem 2010, 5, 1726-1733. [CrossRef] [PubMed]

76. Payne, R.J.; Peyrot, F.; Kerbarh, O.; Abell, A.D.; Abell, C. Rational design, synthesis and evaluation of nanomolar type II dehydroquinase inhibitors. ChemMedChem 2007, 2, 1015-1029. [CrossRef]

77. Prazeres, V.F.V.; Sánchez-Sixto, C.; Castedo, L.; Lamb, H.; Hawkins, A.R.; Riboldi-Tunnicliffe, A.; Coggins, J.R.; Lapthorn, A.J.; González-Bello, C. Nanomolar competitive inhibitors of Mycobacterium tuberculosis and Streptomyces coelicolor type II dehydroquinase. ChemMedChem 2007, 2, 194-207. [CrossRef]

78. Prazeres, V.F.V.; Castedo, L.; Lamb, H.; Hawkins, A.R.; González-Bello, C. 2-Substituted-3-dehydroquinic acids as potent competitive inhibitors of type II dehydroquinase. ChemMedChem 2009, 4, 1980-1984. [CrossRef] [PubMed]

79. Tizón, L.; Otero, J.M.; Prazeres, V.F.V.; Llamas-Saiz, A.L.; Fox, G.C.; Van Raaij, M.J.; Lamb, H.; Hawkins, A.R.; Ainsa, J.A.; Castedo, L.; et al. A prodrug approach for improving antituberculosis activity of potent Mycobacterium tuberculosis type II dehydroquinase inhibitors. J. Med. Chem. 2011, 54, 6063-6084. [CrossRef] [PubMed]

80. Yao, Y.; Ze-Sheng, L. Structure-and-Mechanism-Based Design and Discovery of Type II Mycobacterium tuberculosis Dehydroquinate Dehydratase Inhibitors. Curr. Top. Med. Chem. 2014, 14, 51-63. [CrossRef] [PubMed]

81. Lone, M.Y.; Athar, M.; Gupta, V.K.; Jha, P.C. Prioritization of natural compounds against Mycobacterium tuberculosis 3-dehydroquinate dehydratase: A combined in-silico and in-vitro study. Biochem. Biophys. Res. Commun. 2017, 491, 1105-1111. [CrossRef]

82. Yaniv, H.; Gilvarg, C. Aromatic Biosynthesis XIV. 5-Dehydroshikimic Reductase. J. Chem. Inf. Model. 1955, 213, 787-795.

83. Michel, G.; Roszak, A.W.; Sauvé, V.; Maclean, J.; Matte, A.; Coggins, J.R.; Cygler, M.; Lapthorn, A.J. Structures of shikimate dehydrogenase AroE and its paralog YdiB: A common structural framework for different activities. J. Biol. Chem. 2003, 278, 19463-19472. [CrossRef] 
84. Zhang, X.; Zhang, S.; Hao, F.; Lai, X.; Yu, H.; Huang, Y.; Wang, H. Expression, purification and properties of shikimate dehydrogenase from Mycobacterium tuberculosis. J. Biochem. Mol. Biol. 2005, 38, 624-631. [CrossRef] [PubMed]

85. Fonseca, I.O.; Magalhães, M.L.B.; Oliveira, J.S.; Silva, R.G.; Mendes, M.A.; Palma, M.S.; Santos, D.S.; Basso, L.A. Functional shikimate dehydrogenase from Mycobacterium tuberculosis H37Rv: Purification and characterization. Protein Expr. Purif. 2006, 46, 429-437. [CrossRef] [PubMed]

86. Padyana, A.K.; Burley, S.K. Crystal structure of shikimate 5-dehydrogenase (SDH) bound to NADP: Insights into function and evolution. Structure 2003, 11, 1005-1013. [CrossRef]

87. Kubota, T.; Tanaka, Y.; Hiraga, K.; Inui, M.; Yukawa, H. Characterization of shikimate dehydrogenase homologues of Corynebacterium glutamicum. Appl. Microbiol. Biotechnol. 2013, 97, 8139-8149. [CrossRef] [PubMed]

88. Giles, N.H.; Case, M.E.; Baum, J.; Geever, R.; Huiet, L.; Patel, V.; Tyler, B. Gene organization and regulation in the qa (quinic acid) gene cluster of Neurospora crassa. Microbiol. Rev. 1985, 49, 338-358. [CrossRef]

89. Hawkins, A.R.; Lamb, H.K.; Smith, M.; Keyte, J.W.; Roberts, C.F. Molecular organisation of the quinic acid utilization (QUT) gene cluster in Aspergillus nidulans. MGG Mol. Gen. Genet. 1988, 214, 224-231. [CrossRef]

90. Peek, J.; Christendat, D. The shikimate dehydrogenase family: Functional diversity within a conserved structural and mechanistic framework. Arch. Biochem. Biophys. 2015, 566, 85-99. [CrossRef]

91. Guo, J.; Frost, J.W. Synthesis of aminoshikimic acid. Org. Lett. 2004, 6, 1585-1588. [CrossRef]

92. Peek, J.; Garcia, C.; Lee, J.; Christendat, D. Insights into the function of RifI2: Structural and biochemical investigation of a new shikimate dehydrogenase family protein. Biochim. Biophys. Acta. - Proteins Proteomics. 2013, 1834, 516-523. [CrossRef] [PubMed]

93. Choorapoikayil, S.; Schoepe, J.; Buchinger, S.; Schomburg, D. Analysis of in vivo function of predicted isoenzymes-a metabolomic approach. Omi. A J. Integr. Biol. 2012, 16, 668-680. [CrossRef] [PubMed]

94. Peek, J.; Lee, J.; Hu, S.; Senisterra, G.; Christendat, D. Structural and mechanistic analysis of a novel class of shikimate dehydrogenases: Evidence for a conserved catalytic mechanism in the shikimate dehydrogenase family. Biochemistry 2011, 50, 8616-8627. [CrossRef] [PubMed]

95. Fonseca, I.O.; Silva, R.G.; Fernandes, C.L.; de Souza, O.N.; Basso, L.A.; Santos, D.S. Kinetic and chemical mechanisms of shikimate dehydrogenase from Mycobacterium tuberculosis. Arch. Biochem. Biophys. 2007, 457, 123-133. [CrossRef] [PubMed]

96. Arcuri, H.A.; Borges, J.C.; Fonseca, I.O.; Pereira, J.H.; Neto, J.R.; Basso, L.A.; Santos, D.S.; De Azevedo, W.F. Structural studies of shikimate 5-dehydrogenase from Mycobacterium tuberculosis. Proteins Struct. Funct. Genet. 2008, 72, 720-730. [CrossRef] [PubMed]

97. Bagautdinov, B.; Kunishima, N. Crystal Structures of Shikimate Dehydrogenase AroE from Thermus thermophilus HB8 and its Cofactor and Substrate Complexes: Insights into the Enzymatic Mechanism. J. Mol. Biol. 2007, 373, 424-438. [CrossRef]

98. Singh, S.A.; Christendat, D. Structure of Arabidopsis dehydroquinate dehydratase-shikimate dehydrogenase and implications for metabolic channeling in the shikimate pathway. Biochemistry 2006, 45, 7787-7796. [CrossRef]

99. Han, C.; Hu, T.; Wu, D.; Qu, S.; Zhou, J.; Ding, J.; Shen, X.; Qu, D.; Jiang, H. X-ray crystallographic and enzymatic analyses of shikimate dehydrogenase from Staphylococcus epidermidis: Implications for substrate binding and conformational change. FEBS J. 2009, 276, 1125-1139. [CrossRef]

100. Balinsky, D.; Dennis, A.W.; Cleland, W.W. Kinetic and Isotope-Exchange Studies on Shikimate Dehydrogenase from Pisum sativum. Biochemistry 1971, 10, 1947-1952.

101. Avitia-Domínguez, C.; Sierra-Campos, E.; Salas-Pacheco, J.M.; Nájera, H.; Rojo-Domínguez, A.; Cisneros-Martínez, J.; Téllez-Valencia, A. Inhibition and biochemical characterization of methicillin-resistant Staphylococcus aureus shikimate dehydrogenase: An in silico and kinetic study. Molecules 2014, 19, 4491-4509. [CrossRef]

102. Lim, S.; Schröder, I.; Monbouquette, H.G. A thermostable shikimate 5-dehydrogenase from the archaeon Archaeoglobus fulgidus. FEMS Microbiol. Lett. 2004, 238, 101-106. [PubMed]

103. Park, A.; Lamb, H.K.; Nichols, C.; Moore, J.D.; Brown, K.A.; Cooper, A.; Charles, I.G.; Stammers, D.K.; Hawkins, A.R. Biophysical and kinetic analysis of wild-type and site-directed mutants of the isolated and native dehydroquinate synthase domain of the AROM protein. Protein Sci. 2004, 13, 2108-2119. [CrossRef] 
104. Gan, J.; Wu, Y.; Prabakaran, P.; Gu, Y.; Li, Y.; Andrykovitch, M.; Liu, H.; Gong, Y.; Yan, H.; Ji, X. Structural and biochemical analyses of shikimate dehydrogenase AroE from Aquifex aeolicus: Implications for the catalytic mechanism. Biochemistry 2007, 46, 9513-9522. [CrossRef] [PubMed]

105. Rodrigues-Junior, V.; Breda, A.; Santos, D.; Basso, L. The conserved Lysine69 residue plays a catalytic role in Mycobacterium tuberculosis shikimate dehydrogenase. BMC Res. Notes. 2009, 2, 1-7.

106. Dansette, P.; Azerad, R. The shikimate pathway: II. Stereospecificity of hydrogen transfer catalyzed by NADPH-dehydroshikimate reductase of E. coli. Biochimie. 1974, 56, 751-755. [CrossRef]

107. Han, C.; Wang, L.; Yu, K.; Chen, L.; Hu, L.; Chen, K.; Jiang, H.; Shen, X. Biochemical characterization and inhibitor discovery of shikimate dehydrogenase from Helicobacter pylori. FEBS J. 2006, 273, 4682-4692. [CrossRef]

108. Peek, J.; Shi, T.; Christendat, D. Identification of novel polyphenolic inhibitors of shikimate dehydrogenase (AroE). J. Biomol. Screen. 2014, 19, 1090-1098. [CrossRef]

109. Díaz-Quiroz, D.C.; Cardona-Félix, C.S.; Viveros-Ceballos, J.L.; Reyes-González, M.A.; Bolívar, F.; Ordoñez, M.; Escalante, A. Synthesis, biological activity and molecular modelling studies of shikimic acid derivatives as inhibitors of the shikimate dehydrogenase enzyme of Escherichia coli. J. Enzyme Inhib. Med. Chem. 2018, 33, 397-404. [CrossRef]

110. Enríquez-Mendiola, D.; Téllez-Valencia, A.; Sierra-Campos, E.; Campos-Almazán, M.; Valdez-Solana, M.; Gómez Palacio-Gastélum, M.; Avitia-Domínguez, C. Kinetic and molecular dynamic studies of inhibitors of shikimate dehydrogenase from methicillin-resistant Staphylococcus aureus. Chem. Biol. Drug Des. 2019, 94, 1504-1517. [CrossRef]

111. Li, Z.; Liu, Y.; Bai, X.; Deng, Q.; Wang, J.; Zhang, G.; Xiao, C.; Mei, Y.; Wang, Y. SAR studies on 1,2,4-triazolo[3,4-b][1,3,4]thiadiazoles as inhibitors of Mtb shikimate dehydrogenase for the development of novel antitubercular agents. RSC Adv. 2015, 5, 97089-97101. [CrossRef]

112. Li, Z.; Bai, X.; Deng, Q.; Zhang, G.; Zhou, L.; Liu, Y.; Wang, J.; Wang, Y. Preliminary SAR and biological evaluation of antitubercular triazolothiadiazine derivatives against drug-susceptible and drug-resistant $M t b$ strains. Bioorganic Med. Chem. 2017, 25, 213-220. [CrossRef] [PubMed]

113. Deng, Q.; Meng, J.; Liu, Y.; Guan, Y.; Xiao, C. IMB-SD62, a triazolothiadiazoles derivative with promising action against tuberculosis. Tuberculosis 2018, 112, 37-44. [CrossRef] [PubMed]

114. Isa, M.A.; Majumdar, R.S.; Haider, S. In silico identification of potential inhibitors against shikimate dehydrogenase through virtual screening and toxicity studies for the treatment of tuberculosis. Int. Microbiol. 2019, 22, 7-17. [CrossRef] [PubMed]

115. Hartmann, M.D.; Bourenkov, G.P.; Oberschall, A.; Strizhov, N.; Bartunik, H.D. Mechanism of phosphoryl transfer catalyzed by shikimate kinase from Mycobacterium tuberculosis. J. Mol. Biol. 2006, 364, 411-423. [CrossRef]

116. Cheng, W.C.; Chen, Y.F.; Wang, H.J.; Hsu, K.C.; Lin, S.C.; Chen, T.J.; Yang, J.M.; Wang, W.C. Structures of Helicobacter pylori shikimate kinase reveal a selective inhibitor-induced-fit mechanism. PLOS ONE 2012, 7, e33481. [CrossRef]

117. Blanco, B.; Prado, V.; Lence, E.; Otero, J.M.; García-Doval, C.; Van Raaij, M.J.; Llamas-Saiz, A.L.; Lamb, H.; Hawkins, A.R.; González-Bello, C. Mycobacterium tuberculosis shikimate kinase inhibitors: Design and simulation studies of the catalytic turnover. J. Am. Chem. Soc. 2013, 135, 12366-12376. [CrossRef]

118. Whipp, M.J.; Pittard, A.J. A reassessment of the relationship between aroK-and aroL-encoded shikimate kinase enzymes of Escherichia coli. J. Bacteriol. 1995, 177, 1627-1629. [CrossRef]

119. Gu, Y.; Reshetnikova, L.; Li, Y.; Wu, Y.; Yan, H.; Singh, S.; Ji, X. Crystal structure of shikimate kinase from Mycobacterium tuberculosis reveals the dynamic role of the LID domain in catalysis. J. Mol. Biol. 2002, 319, 779-789. [CrossRef]

120. Vonrhein, C.; Schlauderer, G.J.; Schulz, G.E. Movie of the structural changes during a catalytic cycle of nucleoside monophosphate kinases. Structure 1995, 3, 483-490. [CrossRef]

121. Favela-Candia, A.; Téllez-Valencia, A.; Campos-Almazán, M.; Sierra-Campos, E.; Valdez-Solana, M.; Oria-Hernández, J.; Castillo-Villanueva, A.; Nájera, H.; Avitia-Domínguez, C. Biochemical, Kinetic and Computational Structural Characterization of Shikimate Kinase from Methicillin-Resistant Staphylococcus aureus. Mol. Biotechnol. 2019, 61, 274-285. [CrossRef] 
122. Dhaliwal, B.; Nichols, C.E.; Ren, J.; Lockyer, M.; Charles, I.; Hawkins, A.R.; Stammers, D.K. Crystallographic studies of shikimate binding and induced conformational changes in Mycobacterium tuberculosis shikimate kinase. FEBS Lett. 2004, 574, 49-54. [CrossRef]

123. Simithy, J.; Reeve, N.; Hobrath, J.V.; Reynolds, R.C.; Calderon, A.I. Identification of shikimate kinase inhibitors among anti-Mycobacterium tuberculosis compounds by LC-MS. Tuberculosis 2014, 94, 152-158. [CrossRef]

124. Krell, T.; Maclean, J.; Boam, D.J.; Cooper, A.; Resmini, M.; Brocklehurst, K.; Kelly, S.M.; Price, N.C.; Lapthorn, A.J.; Coggins, J.R. Biochemical and X-ray crystallographic studies on shikimate kinase: The important structural role of the P-loop lysine. Protein Sci. 2001, 10, 1137-1149. [CrossRef]

125. Rosado, L.A.; Vasconcelos, I.B.; Palma, M.S.; Frappier, V.; Najmanovich, R.J.; Santos, D.S.; Basso, L.A. The mode of action of recombinant Mycobacterium tuberculosis shikimate kinase: Kinetics and thermodynamics analyses. PLoS ONE 2013, 8, e61918. [CrossRef]

126. Prado, V.; Lence, E.; Vallejo, J.A.; Beceiro, A.; Thompson, P.; Hawkins, A.R.; Gonzalez-Bello, C. Study of the Phosphoryl-Transfer Mechanism of Shikimate Kinase by NMR Spectroscopy. Chem. Eur. J. 2016, 22, 2758-2768. [CrossRef]

127. Simithy, J.; Fuanta, N.R.; Alturki, M.; Hobrath, J.V.; Wahba, A.E.; Pina, I.; Rath, J.; Hamann, M.T.; DeRuiter, J.; Goodwin, D.C.; et al. Slow-Binding Inhibition of Mycobacterium tuberculosis Shikimate Kinase by Manzamine Alkaloids. Biochemistry 2018, 57, 4923-4933. [CrossRef] [PubMed]

128. Alturki, M.S.; Fuanta, N.R.; Jarrard, M.A.; Hobrath, J.V.; Goodwin, D.C.; Rants'o, T.A.; Calderón, A.I. A multifaceted approach to identify non-specific enzyme inhibition: Application to Mycobacterium tuberculosis shikimate kinase. Bioorg. Med. Chem. Lett. 2018, 28, 802-808. [CrossRef] [PubMed]

129. Rajput, V.S.; Mehra, R.; Kumar, S.; Nargotra, A.; Singh, P.P.; Khan, I.A. Screening of antitubercular compound library identifies novel shikimate kinase inhibitors of Mycobacterium tuberculosis. Appl. Microbiol. Biotechnol. 2016, 100, 5415-5426. [CrossRef] [PubMed]

130. Oliveira, J.S.; Mendes, M.A.; Palma, M.S.; Basso, L.A.; Santos, D.S. One-step purification of 5-enolpyruvylshikimate-3-phosphate synthase enzyme from Mycobacterium tuberculosis. Protein Expr. Purif. 2003, 28, 287-292. [CrossRef]

131. Oliveira, J.S.; Pinto, C.A.; Basso, L.A.; Santos, D.S. Cloning and overexpression in soluble form of functional shikimate kinase and 5-enolpyruvylshikimate 3-phosphate synthase enzymes from Mycobacterium tuberculosis. Protein Expr. Purif. 2001, 22, 430-435. [CrossRef] [PubMed]

132. Vaso, A.; Santos, D.S.; Basso, L.A.; Palma, M.S. Hydrogen/deuterium exchange mass spectrometry for characterizing phosphoenolpyruvate-induced structural transitions in Mycobacterium tuberculosis 5-enolpyruvylshikimate-3-phosphate synthase (EC 2.5.1.1). Int. J. Mass Spectrom. 2011, 302, 12-18. [CrossRef]

133. Marques, M.R.; Pereira, J.H.; Oliveira, J.S.; Basso, L.A.; de Azevedo, W.F., Jr.; Santos, D.S.; Palma, M.S. The inhibition of 5-enolpyruvylshikimate-3-phosphate synthase as a model for development of novel antimicrobials. Curr. Drug Targets. 2007, 8, 445-457. [CrossRef] [PubMed]

134. Marques, M.R.; Vaso, A.; Neto, J.R.; Fossey, M.A.; Oliveira, J.S.; Basso, L.A.; Santos, D.S.; Azevedo, W.F., Jr.; Palma, M.S. Dynamics of glyphosate-induced conformational changes of Mycobacterium tuberculosis 5-enolpyruvylshikimate-3-phosphate synthase (EC 2.5.1.19) determined by hydrogen-deuterium exchange and electrospray mass spectrometry. Biochemistry 2008, 47, 7509-7522. [CrossRef]

135. Stallings, W.C.; Abdel-Meguid, S.S.; Lim, L.W.; Shieh, H.S.; Dayringer, H.E.; Leimgruber, N.K.; Kishore, G.M. Structure and topological symmetry of the glyphosate target 5-enolpyruvylshikimate-3-phosphate synthase: A distinctive protein fold. Proc. Natl. Acad. Sci. USA 1991, 88, 5046-5050. [CrossRef]

136. Funke, T.; Healy-Fried, M.L.; Han, H.; Alberg, D.G.; Bartlett, P.A.; Schönbrunn, E. Differential inhibition of class I and class II 5-enolpyruvylshikimate-3-phosphate synthases by tetrahedral reaction intermediate analogues. Biochemistry 2007, 46, 13344-13351. [CrossRef]

137. Clark, M.E.; Berti, P.J. Enolpyruvyl activation by enolpyruvylshikimate-3-phosphate synthase. Biochemistry 2007, 46, 1933-1940. [CrossRef]

138. Lou, M.; Burger, S.K.; Gilpin, M.E.; Gawuga, V.; Capretta, A.; Berti, P.J. Transition state analysis of enolpyruvylshikimate 3-phosphate (EPSP) synthase (aroA)-catalyzed EPSP hydrolysis. J. Am. Chem. Soc. 2012, 134, 12958-12969. [CrossRef]

139. Dos Santos, A.M.; Lima, A.H.; Alves, C.N.; Lameira, J. Unraveling the Addition-Elimination Mechanism of EPSP Synthase through Computer Modeling. J. Phys. Chem. B 2017, 121, 8626-8637. [CrossRef] [PubMed] 
140. Steinrücken, H.C.; Amrhein, N. The herbicide glyphosate is a potent inhibitor of 5-enolpyruvylshikimic acid-3-phosphate synthase. Biochem. Biophys. Res. Commun. 1980, 94, 1207-1212. [CrossRef]

141. Sergiev, I.G.; Alexieva, V.S.; Ivanov, S.V.; Moskova, I.I.; Karanov, E.N. The phenylurea cytokinin 4PU-30 protects maize plants against glyphosate action. Pestic Biochem. Physiol. 2006, 85, 139-146. [CrossRef]

142. Haghani, K.; Salmanian, A.H.; Ranjbar, B.; Zakikhan-Alang, K.; Khajeh, K. Comparative studies of wild type Escherichia coli 5-enolpyruvylshikimate 3-phosphate synthase with three glyphosate-insensitive mutated forms: Activity, stability and structural characterization. Biochim. Biophys. Acta. 2008, 1784, 1167-1175. [CrossRef]

143. Ramachandran, V.; Singh, R.; Yang, X.; Tunduguru, R.; Mohapatra, S.; Khandelwal, S.; Datta, S. Genetic and chemical knockdown: A complementary strategy for evaluating an anti-infective target. Adv. Appl. Bioinform. Chem. 2013, 6, 1-13. [CrossRef]

144. Borges, J.C.; Pereira, J.H.; Vasconcelos, I.B.; Santos, G.C.; Olivieri, J.R.; Ramos, C.H.I.; Palma, M.S.; Basso, L.A.; Santos, D.S.; Azevedo, W.F., Jr. Phosphate closes the solution structure of the 5-enolpyruvylshikimate-3-phosphate synthase (EPSPS) from Mycobacterium tuberculosis. Arch. Biochem. Biophys. 2006, 452, 156-164. [CrossRef] [PubMed]

145. Timmers, L.F.S.M.; Neto, A.M.; Montalvão, R.W.; Basso, L.A.; Santos, D.S.; de Souza, O.N. EPSP synthase flexibility is determinant to its function: Computational molecular dynamics and metadynamics studies. J. Mol. Model. 2017, 23, 197. [CrossRef]

146. Priestman, M.A.; Healy, M.L.; Becker, A.; Alberg, D.G.; Bartlett, P.A.; Lushington, G.H.; Schönbrunn, E. Interaction of phosphonate analogues of the tetrahedral reaction intermediate with 5-enolpyruvylshikimate-3-phosphate synthase in atomic detail. Biochemistry. 2005, 44, 3241-3248. [CrossRef] [PubMed]

147. Tian, Y.S.; Xu, J.; Han, J.; Zhao, W.; Fu, X.Y.; Peng, R.H.; Yao, Q.H. Complementary screening, identification and application of a novel class II 5-enopyruvylshikimate-3-phosphate synthase from Bacillus cereus. World J. Microbiol. Biotechnol. 2013, 29, 549-557. [CrossRef]

148. Dias, M.V.; Ely, F.; Canduri, F.; Pereira, J.H.; Frazzon, J.; Basso, L.A.; Santos, D.S. Crystallization and preliminary X-ray crystallographic analysis of chorismate synthase from Mycobacterium tuberculosis. Acta Crystallogr. D: Biol. Crystallogr. 2004, 60, 2003-2005. [CrossRef] [PubMed]

149. Ely, F.; Nunes, J.E.; Schroeder, E.K.; Frazzon, J.; Palma, M.S.; Santos, D.S.; Basso, L.A. The Mycobacterium tuberculosis Rv2540c DNA sequence encodes a bifunctional chorismate synthase. BMC Biochem. 2008, 9, 13. [CrossRef]

150. Dias, M.V.; Borges, J.C.; Ely, F.; Pereira, J.H.; Canduri, F.; Ramos, C.H.; de Azevedo, W.F., Jr. Structure of chorismate synthase from Mycobacterium tuberculosis. J. Struct. Biol. 2006, 154, 130-143. [CrossRef]

151. Arcuri, H.; Palma, M. Understanding the structure, activity and inhibition of chorismate synthase from Mycobacterium tuberculosis. Curr. Med. Chem. 2011, 18, 1311-1317. [CrossRef]

152. Dias, M.V.; Ely, F.; Palma, M.S.; Azevedo, W.F., Jr.; Basso, L.A.; Santos, D.S. Chorismate synthase: An attractive target for drug development against orphan diseases. Curr. Drug Targets. 2007, 8, 437-444. [CrossRef]

153. Khera, H.K.; Singh, S.K.; Mir, R.; Bharadwaj, V.; Singh, S. A HR-MS based method for the determination of Chorismate Synthase activity. Protein Pep. Lett. 2017, 24, 229-234. [CrossRef]

154. Lawan, N. QM-MM investigation on chorismate synthase enzyme role. Chiang Mai, J. Sci. 2014, 41, 618-626.

155. Lawan, N.; Chasing, P.; Santatiwongchai, J.; Muangpil, S. QM/MM molecular modelling on mutation effect of chorismate synthase enzyme catalysis. J. Mol. Graph. Model. 2019, 87, 250-256. [CrossRef]

156. Lawan, N.; Ranaghan, K.E.; Manby, F.R.; Mulholland, A.J. Comparison of DFT and ab initio QM/MM methods for modelling reaction in chorismate synthase. Chem. Phys. Lett. 2014, 608, 380-385. [CrossRef]

157. Thomas, M.G.; Lawson, C.; Allanson, N.M.; Leslie, B.W.; Bottomley, J.R.; McBride, A.; Olusanya, O.A. A series of 2 (Z)-2-benzylidene-6, 7- dihydroxybenzofuran-3 [2H]-ones as inhibitors of chorismate synthase. Bioorg. Med. Chem. Lett. 2003, 13, 423-426. [CrossRef]

158. Pitchandi, P.; Hopper, W.; Rao, R. Comprehensive database of chorismate synthase enzyme from shikimate pathway in pathogenic bacteria. BMC Pharmacol. Toxicol. 2013, 14, 29. [CrossRef]

159. Fernandes, C.L.; Breda, A.; Santos, D.S.; Basso, L.A.; Souza, O.N. A structural model for chorismate synthase from Mycobacterium tuberculosis in complex with coenzyme and substrate. Comput. Biol. Med. 2007, 37, 149-158. [CrossRef] 
160. Ling, L.L.; Schneider, T.; Peoples, A.J.; Spoering, A.L.; Engels, I.; Conlon, B.P.; Mueller, A.; Schäberle, T.F.; Hughes, D.E.; Epstein, S.; et al. A new antibiotic kills pathogens without detectable resistance. Nature 2015, 517, 455-459. [CrossRef] [PubMed]

161. Iyer, A.; Madder, A.; Singh, I. Teixobactins: A new class of 21st century antibiotics to combat multidrug-resistant bacterial pathogens. Future Microbiol. 2019, 14, 457-460. [CrossRef] [PubMed]

162. Basaraba, R.J.; Ojha, A.K. Mycobacterial Biofilms: Revisiting Tuberculosis Bacilli in Extracellular Necrotizing Lesions. Microbiol. Spectr. 2017, 5, 1-7. [CrossRef] [PubMed]

163. Flentie, K.; Harrison, G.A.; Tükenmez, H.; Livny, J.; Good, J.A.D.; Sarkar, S.; Zhu, D.X.; Kinsella, R.L.; Weiss, L.A.; Solomon, S.D.; et al. Chemical disarming of isoniazid resistance in Mycobacterium tuberculosis. Proc. Natl. Acad. Sci. USA 2019, 116, 10510-10517. [CrossRef] [PubMed]

164. Machado, P.; Bizarro, C.V.; Basso, L.A. Resistance Reversed in KatG Mutants of Mycobacterium tuberculosis. Trends Microbiol. 2019, 27, 655-656. [CrossRef] [PubMed]

165. Baindara, P. Host-directed therapies to combat tuberculosis and associated non-communicable diseases. Microb. Pathog. 2019, 130, 156-168. [CrossRef]

166. Frank, D.J.; Horne, D.J.; Dutta, N.K.; Shaku, M.T.; Madensein, R.; Hawn, T.R.; Steyn, A.J.C.; Karakousis, P.C.; Kana, B.D.; Meintjes, G.; et al. Remembering the host in tuberculosis drug development. J. Infect. Dis. 2019, 219, 1518-1524. [CrossRef]

167. Johnson, E.O.; LaVerriere, E.; Office, E.; Stanley, M.; Meyer, E.; Kawate, T.; Gomez, J.E.; Audette, R.E.; Bandyopadhyay, N.; Betancourt, N.; et al. Large-scale chemical-genetics yields new M. tuberculosis inhibitor classes. Nature 2019, 571, 72-78. [CrossRef]

168. Katsuno, K.; Burrows, J.N.; Duncan, K.; Van Huijsduijnen, R.H.; Kaneko, T.; Kita, K.; Mowbray, C.E.; Schmatz, D.; Warner, P.; Slingsby, B.T. Hit and lead criteria in drug discovery for infectious diseases of the developing world. Nat. Rev. Drug Discov. 2015, 14, 751-758. [CrossRef]

(C) 2020 by the authors. Licensee MDPI, Basel, Switzerland. This article is an open access article distributed under the terms and conditions of the Creative Commons Attribution (CC BY) license (http://creativecommons.org/licenses/by/4.0/). 